\title{
ESTUDO QUÍMICO E ATIVIDADE ANTIBACTERIANA DO CAULE DE Aristolochia esperanzae Kuntze (ARISTOLOCHIACEAE)
}

\author{
Alison G. Pacheco, Thiago M. Silva, Rozângela M. Manfrini, William S. T. Sallum, Lucienir Pains Duarte, Dorila Piló- \\ Veloso e Antônio F. de C. Alcântara* \\ Departamento de Química, Instituto de Ciências Exatas, Universidade Federal de Minas Gerais, Av. Presidente Antônio Carlos, \\ 6627, 31260-901 Belo Horizonte - MG, Brasil \\ Vagner F. Knupp \\ Fundação Centro Tecnológico de Minas Gerais, Av. José Cândido da Silveira, 2000, 31170-000 Belo Horizonte - MG, Brasil
}

Recebido em 8/10/09; aceito em 13/5/10; publicado na web em 17/9/10

CHEMICAL STUDY AND ANTIBACTERIAL ACTIVITY OF STEM OF Aristolochia esperanzae Kuntze
(ARISTOLOCHIACEAE). From the ethanolic extract of the stem of A. esperanzae ethyl and methyl fatty acid esters, fatty acids,
aristolochic I and II acids, and $\beta$-cubebin were isolated. In addiction asarinin, populifolic and 2-oxo-populifolic acids, aristolactams
AIa and AII, and sitosterol 3-O- $\beta$-D-glucopyranoside were also isolated and firstly described in the species. Asarinin and $\beta$-cubebin
showed antibacterial activity against Bacillus cereus and aristolochic acid I against Staphylococcus aureus and Listeria monocitogenes.

Keywords: Aristolochia esperanzae; aristolochic acids; antibacterial activity.

\section{INTRODUÇÃO}

Aristolochia esperanzae Kuntze (Aristolochiaceae) tem como sinônimo A. boliviensis O. Kuntze, ${ }^{1}$ sendo encontrada na América do Sul e conhecida popularmente no Brasil como cipó-mil-homens. ${ }^{2}$ Levantamentos etnofarmacológicos indicam o uso de extratos desta espécie no tratamento de artrite reumatoide e de diversas outras doenças. ${ }^{3}$ Por outro lado, a comercialização de ervas medicinais contendo extratos de espécies do gênero Aristolochia é proibida em muitos países, devido as suas propriedades nefrotóxicas, carcinogênicas e mutagênicas, ${ }^{4}$ que podem levar tanto à nefropatia progressiva quanto ao câncer urotelial em humanos. ${ }^{5}$

O gênero Aristolochia tem sido documentado quimicamente desde $1951,{ }^{6}$ revelando principalmente a presença de terpenoides, lignoides, flavonoides, ácidos graxos e constituintes nitrogenados (alcaloides e nitrofenantrenos). ${ }^{7}$ A literatura registra estudos fitoquímicos das folhas e raízes de A. esperanzae ${ }^{8}$ das quais foram isolados diterpenos dos tipos clerodano e labdano, triterpenos, lignanas dos tipos dibenzilbutirolactona, furofurano tetra-hidrofurano e 4-aril-tetralona, ácidos aristolóquicos e aristolactamas. O presente trabalho descreve o estudo fitoquímico do caule (cerne e cascas) de A. esperanzae, resultando no isolamento de asarinina (1), ácido pupolifólico (2), ácido 2-oxo-pupolifólico (3), ácido aristolóquico II (4), aristolactama AII (5), aristolactama AIa (6), $\left(8 R, 8^{\prime} R, 9 S\right)$-cubebina ou $\beta$-cubebina (7), ácido aristolóquico I (8), sitosterol-3- $O$ - $\beta$-D-glicopiranosídeo $(\mathbf{9}) \mathrm{e}$ estigmastan-3,5,22-trieno (10), conforme Figura 1. Os compostos 4, 7 e 8 haviam sido anteriormente isolados nas folhas e raízes da planta e os demais estão sendo descritos pela primeira vez na espécie. Além disto, este estudo foi acompanhado por testes de atividade antibacteriana de seus extratos, frações e fitoconstituintes isolados.

\section{PARTE EXPERIMENTAL}

\section{Procedimentos gerais}

Os pontos de fusão não corrigidos foram determinados em aparelho Mettler FP80 SNR H22439. As análises por espectroscopia

*e-mail: aalcantara@zeus.qui.ufmg.br de absorção na região do infravermelho (IV) foram realizadas em espectrômetro Perkin Elmer Spectrum One (ATR). As análises por cromatografia a gás acoplada à espectrometria de massas (CG/EM) foram realizadas em um cromatógrafo CG Varian 3800, acoplado a um espectrômetro de massas Varian Saturno 4000. As condições de análises foram: coluna $5 \%$ fenil $95 \%$ polidimetilsiloxano $(30 \mathrm{~m} \mathrm{x}$ $0,25 \mathrm{~mm} \times 0,25 \mu \mathrm{m}$ de filme); hélio como gás de arraste com fluxo de $1 \mathrm{~mL} / \mathrm{min}$; injetor com programação de temperatura a $250{ }^{\circ} \mathrm{C} \mathrm{com}$ rampa de $200{ }^{\circ} \mathrm{C} / \mathrm{min}$ até $300{ }^{\circ} \mathrm{C}$; injeções em modo split de $1: 15$; interface operante a $300{ }^{\circ} \mathrm{C}$ com energia de ionização de $70 \mathrm{eV}$. Para análise de 9 a programação de temperatura foi isotérmica a $300^{\circ} \mathrm{C}$, por $40 \mathrm{~min}$; para 10 , foi a $50{ }^{\circ} \mathrm{C}$ por $5 \mathrm{~min}, 10{ }^{\circ} \mathrm{C} / \mathrm{min}$ até $300{ }^{\circ} \mathrm{C}$, por $30 \mathrm{~min}$; para as demais amostras, foi a $80{ }^{\circ} \mathrm{C}, 7 \mathrm{~min}, 10^{\circ} \mathrm{C} / \mathrm{min}$ até $300^{\circ} \mathrm{C}$, por $40 \mathrm{~min}$. A identificação dos componentes por CG/ EM baseou-se na comparação eletrônica do padrão de fragmentação dos componentes nos respectivos espectros de massas com aqueles da biblioteca do banco de dados NIST (2005).

As análises por espectroscopia de ressonância magnética nuclear (RMN) foram realizadas em espectrômetros Bruker DPX-200 e DRX400 linha Avance. Os deslocamentos químicos foram registrados em unidade $\delta$ (em ppm) e as constantes de acoplamento $(J)$ em Hz. Tetrametilsilano (TMS) foi empregado como padrão de referência interna, tendo $\mathrm{CDCl}_{3}$ ou DMSO- $d_{6}$ como solvente.

Nas cromatografias em camada delgada (CCD) foram empregadas placas de vidro recobertas por sílica gel $60 \mathrm{G}$ Merck com $0,25 \mathrm{~mm}$ de espessura e ativadas a $100{ }^{\circ} \mathrm{C}$. Nas cromatografias em coluna (CC) foram empregadas colunas de vidro de diversos diâmetros e eluição na maioria das vezes sob pressão atmosférica. As fases estacionárias utilizadas foram sílica gel 60 Merck (70-230 mesh), sílica gel 60 Merck impregnada com 5\% de $\mathrm{AgNO}_{3}$ e Sephadex LH-20. As frações contendo clorofila foram tratadas com carvão ativo. ${ }^{9}$ Luz ultravioleta ( $\lambda=254$ e $366 \mathrm{~nm}$ ), vapores de iodo e solução vanilina/ácido perclórico foram empregados como reveladores na CCD.

Os bioensaios foram realizados empregando-se bactérias Grampositivas (Staphylococcus aureus ATCC 29213, Bacillus cereus ATCC 11779 e Listeria monocytogenes ATCC 15313) e Gram-negativas (Escherichia coli ATCC 25723, Salmonela typhimurium ATCC 14028 e Citrobacter freundi ATCC 8090). 


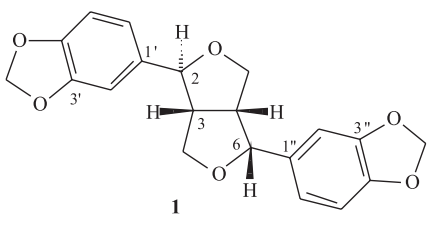<smiles>[R]c1cccc2c1cc1[nH]c(=O)c3cc(O)c(OC)c1c32</smiles><smiles>CCC(CCC(C)C1CCC2[C@H]3CC=C4CC(O[C@@H]5OC(CO)[C@@H](O)[C@H](O)[C@H]5O)CC[C@]4(C)C3CCC12C)C(C)C</smiles>

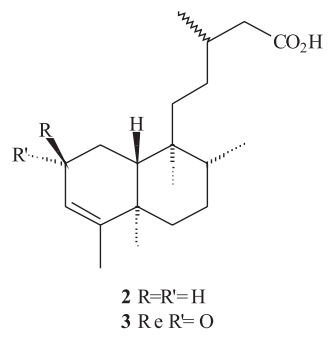<smiles>[R]c1cc([R])c2cc([N+](=O)[O-])c(C(=O)O)c([N+](=O)[O-])c2c1</smiles>

$4 \mathrm{R}=\mathrm{R}^{\prime}=\mathrm{H}$
$8 \mathrm{R}=\mathrm{H} ; \mathrm{R}^{\prime}=\mathrm{OMe}$<smiles>O[C@@H]1OC[C@@H](Cc2ccc3c(c2)OCO3)[C@@H]1Cc1ccc2c(c1)OCO2</smiles>

7

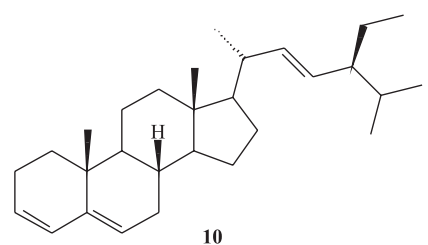

Figura 1. Estrutura química dos constituintes isolados do caule de Aristolochia esperanzae

\section{Material vegetal}

O material vegetal de A. esperanzae foi coletado no Município de Esmeraldas (MG). Uma exsicata da espécie encontra-se depositada no Herbário do Departamento de Botânica do Instituto de Ciências Biológicas da Universidade Federal de Minas Gerais sob o número BHCB 61743. Fotos ilustrativas de A. esperanzae Kuntze podem ser visualizadas em http://farm4.static.flickr. com/3476/3729632198_94598d6320.jpg.

\section{Extração e isolamento dos compostos}

O caule de A. esperanzae foi separado manualmente em cascas e cerne. Após secagem em estufa a $50^{\circ} \mathrm{C}$ e pulverização, cascas $(1,21$ $\mathrm{kg})$ e cerne $(7,00 \mathrm{~kg})$ do caule foram submetidos separadamente à extração a temperatura ambiente com EtOH por 7 dias, obtendo-se os extratos concentrados das cascas (ECA; 189,76 g) e do cerne (ECE; 328,48 g).

ECA foi submetido à $\mathrm{CC}$ de sílica gel, sendo coletadas frações eluídas em hexano, diclorometano (DCM), acetato de etila (AcOEt), $\mathrm{EtOH}$ e $\mathrm{MeOH}$, em gradiente crescente de polaridade. As frações foram reunidas em grupos após análises por CCD. As frações eluídas em hexano:DCM 9:1 apresentaram-se como um óleo amarelado ( $0,02 \mathrm{~g})$, identificado como uma mistura dos seguintes compostos: hexadecanoato de etila $\left(\mathrm{CG} / \mathrm{EM} \mathrm{t}_{\mathrm{R}}=21,522 \mathrm{~min}, \mathrm{~m} / \mathrm{z} 284,3[\mathrm{M}]^{+}\right.$, $239,3,157,2,101,1,88,1,73,1,55,1$ e 43,1$)$, oleato de etila $\left(\mathrm{t}_{\mathrm{R}}=\right.$ 23,154 min, $m / z, 310,4[\mathrm{M}]^{+}, 264,4,211,3,110,2,96,2,83,1,69,1 \mathrm{e}$ $55,1), 15$-metil-heptadecanoato de etila $\left(\mathrm{t}_{\mathrm{R}}=23,383 \mathrm{~min}, \mathrm{~m} / \mathrm{z}, 312,3\right.$ $[\mathrm{M}]^{+}, 269,4,157,2,101,1,88,1,57,1$ e 55,1), ácido docosanoico $\left(\mathrm{t}_{\mathrm{R}}\right.$ $=25,034 \mathrm{~min}, \mathrm{~m} / \mathrm{z} 340,4[\mathrm{M}]^{+}, 295,4,157,2,88,1,71,1,57,1 \mathrm{e} \mathrm{43,1)}$, ácido tricosanoico $\left(\mathrm{t}_{\mathrm{R}}=25,875 \mathrm{~min}, \mathrm{~m} / \mathrm{z}, 354,4[\mathrm{M}]^{+}, 309,3,157,2\right.$, 88,1, 69,2, 55,1 e 43,1), (2,2-dimetil-1,3-dioxolan-4-il)octadecanoato de metila $\left(\mathrm{t}_{\mathrm{R}}=27,376 \mathrm{~min}, \mathrm{~m} / z, 382,5[\mathrm{M}]^{+}, 157,2,101,1,57,1,55,1 \mathrm{e}\right.$ $41,1)$ e 2-metil-hexacosanoato de metila $\left(\mathrm{t}_{\mathrm{R}}=29,452 \mathrm{~min}, \mathrm{~m} / \mathrm{z}, 424,5\right.$ $[\mathrm{M}]^{+}, 157,2,101,1,87,1,69,2,57,1,47,1$ e 43,1).

As frações de ECA eluídas em hexano:DCM 1:1 (5,43 g) foram submetidas a refracionamento por CC de sílica gel, sendo coletadas frações eluídas em hexano, DCM e AcOEt, em gradiente crescente de polaridade. As frações eluídas em hexano:DCM 3:1 foram submetidas à recristalização em EtOH, fornecendo um sólido cristalino branco $(0,11 \mathrm{~g})$ identificado como $\mathbf{1}$, conforme dados de RMN, IV e CG/EM apresentados no material suplementar. ${ }^{11}$ As frações eluídas em hexano:DCM 1:3 (3,86 g) foram submetidas a refracionamento por CC de sílica gel, sendo coletadas frações em hexano, DCM e AcOEt, em gradiente crescente de polaridade. As frações em hexano $(1,23 \mathrm{~g})$ e hexano:DCM 1:1 (0,85 g) foram reunidas e submetidas a fracionamento por $\mathrm{CC}$ de sílica impregnada com $\mathrm{AgNO}_{3}(5 \%) \mathrm{e}$ eluição em cicloexano:AcOEt 1:1, obtendo-se um sólido branco $(0,01$ g) identificado como uma mistura de $\mathbf{2}$ e $\mathbf{3}$, conforme dados de RMN de ${ }^{13} \mathrm{C}$ descritos na literatura. ${ }^{7}$

As frações de ECA eluídas em DCM (2,58 g) forneceram um sólido branco que foi submetido a refracionamento por CC de sílica gel e eluição em DCM e AcOEt, em gradiente crescente de polaridade. As frações em DCM forneceram um sólido ( $0,01 \mathrm{~g}$ ) identificado como 4, conforme dados de RMN, IV e CG/EM apresentados no material suplementar. ${ }^{11}$ As frações de ECA eluídas em DCM:AcOEt 1:1 $(0,12 \mathrm{~g})$ forneceram um sólido branco que foi submetido a refracionamento por $\mathrm{CC}$ de Sephadex e eluição em $\mathrm{MeOH}$, obtendo-se sucessivamente sólidos amarelados identificados como 5 (0,05 g) e 6 (0,01 g), conforme dados de RMN, IV e CG/EM apresentados no material suplementar. ${ }^{12}$

ECE foi submetido à $\mathrm{CC}$ de sílica gel, sendo coletadas frações eluídas em hexano, DCM, AcOEt, EtOH e $\mathrm{MeOH}$, em gradiente crescente de polaridade. As frações de ECE eluídas em DCM (6,24 g) foram submetidas a refracionamento por $\mathrm{CC}$ de sílica e eluição em hexano, DCM e AcOEt em gradiente crescente de polaridade. Das frações eluídas em hexano:DCM 1:3 foi obtido um sólido cristalino branco $(0,01 \mathrm{~g})$ identificado como 7 , conforme dados de RMN e IV apresentados no material suplementar. ${ }^{13}$ As frações de ECE eluídas em DCM:AcOEt 9:1 (4,88 g) foram submetidas a refracionamento por CC de sílica e eluição em DCM e AcOEt, em gradiente crescente de polaridade. As frações obtidas em DCM:AcOEt 1:1 forneceram, após recristalização em $\mathrm{MeOH}$, um sólido amarelado $(0,06 \mathrm{~g})$ identificado como 8, conforme dados de RMN, IV e CG/EM apresentados no material suplementar. ${ }^{12}$ As frações de ECE eluídas em DCM:AcOEt 
1:4 (0,76 g) foram submetidas a fracionamento cromatográfico por Sephadex com eluição em $\mathrm{MeOH}$, fornecendo um sólido branco (0,08 g) identificado como 9, conforme dados de análise elementar (C:70,55\%; H: 10,36\%; O: 19,09\%), no IV e de RMN de ${ }^{1} \mathrm{He}$ de ${ }^{13} \mathrm{C}$ descritos na literatura. ${ }^{10}$

As frações de ECE eluídas em AcOEt (2,59 g) foram recristalizadas em $\mathrm{MeOH}$, fornecendo um sólido branco ( $0,03 \mathrm{~g})$ identificado como 10, conforme dados de CG/EM: $\mathrm{t}_{\mathrm{R}}=50,936 \mathrm{~min}, \mathrm{~m} / \mathrm{z} 394,4$ $[\mathrm{M}]^{+}, 351,4,255,2,189,2,145,2,133,2,107,2,96,2,93,2,81,1$ (pico base) e 55 .

\section{Metodologia biológica}

No teste de difusão em ágar, ${ }^{14}$ os micro-organismos foram inoculados individualmente em tubos de ensaio contendo $2 \mathrm{~mL}$ do meio infuso de cérebro e coração (BHI; 37,0 g/L) e, posteriormente, incubados em estufa a $37^{\circ} \mathrm{C}$ por $18 \mathrm{~h}$. Uma alíquota de $0,5 \mathrm{~mL}$ deste material foi transferida para um tubo contendo $4,5 \mathrm{~mL}$ de solução salina estéril constituída por soluções aquosas de $\mathrm{NaCl}(9,0 \mathrm{~g} / \mathrm{L})$ e $\mathrm{MgSO}_{4} \cdot 7 \mathrm{H}_{2} \mathrm{O}(0,5 \mathrm{~g} / \mathrm{L})$. Foram preparadas placas de Petri contendo o meio de cultura antibiótico $\mathrm{n}^{\circ} 1(27,0 \mathrm{~g} / \mathrm{L})$ e $0,4 \mathrm{~mL}$ do inóculo. Discos contendo $100 \mu \mathrm{g}$ da amostra foram colocados nas placas com o auxílio de uma pinça estéril. Um disco contendo o controle positivo (disco impregnado com o antibiótico cloranfenicol) ou o controle negativo (disco impregnado com o solvente utilizado para solubilizar a amostra) foi colocado no centro de cada placa. As leituras dos halos de inibição foram feitas após 24 h de incubação.

No teste de concentração inibitória mínima, ${ }^{15}$ os micro-organismos foram inoculados em tubos de ensaio contendo o meio BHI $(2,0 \mathrm{~mL})$ e incubados em estufa a $37{ }^{\circ} \mathrm{C}$ por $18 \mathrm{~h}$. Em seguida, $0,5 \mathrm{~mL}$ desta suspensão foi transferida para um tubo contendo $4,5 \mathrm{~mL}$ de solução salina estéril, obtendo-se uma suspensão compatível com a escala 5 de McFarland (inóculo). Para cada amostra a ser testada, foram usados 10 tubos de ensaio contendo $1,8 \mathrm{~mL}$ do meio de cultura $\mathrm{BHI}$ no tubo 1 e 1,0 mL nos demais tubos (tubos 2-10). Um volume de $200 \mu \mathrm{L}$ da solução teste $(1,025 \mathrm{mg}$ de cada amostra dissolvidos em $200 \mu \mathrm{L}$ de DMSO) foi colocado no tubo 1 . Sequencialmente, transferiu-se $1 \mathrm{~mL}$ do tubo 1 para o tubo 2, depois $1 \mathrm{~mL}$ do tubo 2 para o tubo $3 \mathrm{e}$, assim sucessivamente. Desprezou-se $1 \mathrm{~mL}$ do tubo 10. Adicionaram-se 100 $\mu \mathrm{L}$ do inóculo em cada tubo de ensaio. Os tubos foram incubados em estufa a $35^{\circ} \mathrm{C}$ por $18 \mathrm{~h}$. A leitura foi realizada após $18 \mathrm{~h}$ de incubação. Observou-se a partir de qual tubo a mistura se tornara turva. A concentração inibitória mínima (CIM) foi atribuída àquela do tubo que não apresentou turbidez com a menor diluição, sendo, portanto, a menor concentração que inibe o crescimento do micro-organismo teste.

\section{RESULTADOS E DISCUSSÃO}

\section{Análise estrutural dos fitoconstituintes isolados}

Os compostos isolados $\mathbf{1}, \mathbf{4 , 5 , 8}$ e $\mathbf{9}$ foram identificados como sendo, respectivamente, asarinina,,$^{11}$ ácido aristolóquico II,${ }^{11}$ aristolactama AII, ${ }^{12}$ ácido aristolóquico $\mathrm{I}^{12}$ e sitosterol-3- $O-\beta$-Dglicopiranosídeo, ${ }^{10}$ com base na análise dos dados obtidos dos respectivos espectros de IV, EM e RMN uni- e bidimensionais (HMBC, COSY, HMBC e NOESY), bem como pela comparação com dados da literatura.

Os compostos isolados 2, 3, 6 e 7 foram identificados como sendo, respectivamente, ácidos populifólico ${ }^{8}$ e 2-oxo-populifólico, ${ }^{8}$ aristolactama $\mathrm{AIa}^{12}$ e $\left(8 R, 8^{\prime} R, 9 S\right)$-cubebina, ${ }^{13}$ com base na análise dos dados obtidos dos respectivos espectros de IV e RMN uni- e bidimensionais (HMBC, COSY, HMBC e NOESY), bem como pela comparação com dados da literatura. $\mathrm{O}$ composto isolado $\mathbf{1 0}$ foi identificado como sendo estigmastan-3,5,22-trieno, pela comparação eletrônica do padrão de fragmentação dos componentes nos respectivos espectros de massas com aqueles da biblioteca do banco de dados NIST (2005). Ésteres etílicos não são comuns quando originários de fontes vegetais, portanto, os fitoconstituintes isolados desse tipo podem ser derivados formados durante a maceração, já que a extração utilizou EtOH como solvente.

\section{Atividade antibacteriana}

Testes de difusão em ágar e de concentração inibitória mínima (CIM) de ECA e ECE foram realizados frente a diferentes espécies de bactérias. Esses extratos foram ativos somente frente a B. cereus (CIM $256 \mu \mathrm{g} / \mathrm{mL}$ ). B. cereus é uma bactéria termo-resistente encontrada principalmente em cereais e carnes, sendo responsável por doenças de origem alimentar, causando vômito e diarréia. ${ }^{16}$

O fracionamento cromatográfico dos extratos foi biomonitorado por testes de atividade antibacteriana contra $B$. cereus, empregando os sistemas eluentes: hexano, hexano:DCM 9:1, hexano:DCM 3:1, hexano:DCM 1:1, DCM, DCM:AcOEt 1:1, DCM:AcOEt 1:3, AcOEt, AcOEt:EtOH 1:1, EtOH e MeOH. Os testes de halo de inibição apresentaram-se positivos apenas para as respectivas frações dos dois extratos eluídas em hexano:DCM 1:1 e DCM, ambas com CIM de $512 \mu \mathrm{g} / \mathrm{mL}$. Nessas frações do estudo fitoquímico de ECA e ECE foram isolados, respectivamente, 1 e 7 .

Os testes microbiológicos de halo de inibição de $\mathbf{1}$ e $\mathbf{7}$ foram negativos contra $S$. aureus, E. coli e $S$. typhimurium. De forma semelhante aos extratos, os compostos 1 e 7 apresentaram atividades expressivas e seletivas frente a B. cereus (CIM 256 e $512 \mu \mathrm{g} / \mathrm{mL}$, respectivamente). Estes resultados sugeriram que o mecanismo de ação não é por toxicidade, mas envolve fatores que afetam somente o B. cereus, apresentando-se muito importante para o desenvolvimento de antibióticos seletivos e de curto espectro de ação.

Para avaliar a possibilidade de sinergismo entre os compostos $\mathbf{1}$ e 7, foram realizados testes de CIM de misturas destes compostos frente a $B$. cereus. As misturas de 1:7 nas proporções 0,4; 1,1 e 1,9 resultaram em CIM de 256, 512 e $512 \mu \mathrm{g} / \mathrm{mL}$, respectivamente. Esses resultados indicam ausência de sinergismo e maior atividade de 1 frente a $B$. cereus.

Com exceção de $\mathbf{8}$, os demais compostos isolados foram inativos frente a $S$. aureus, E. coli, S. typhimurium, B. cereus, $C$. freundi e $L$. monocytogenes. O ácido aristolóquico I (8) apresentou resultados positivos contra S. aureus e L. monocytogenes (CIM de 256 e $128 \mu \mathrm{g}$ / $\mathrm{mL}$, respectivamente). Este resultado é muito promissor, pois $S$. aureus é uma bactéria contaminante comum do solo, água e alimentos, sendo sua toxina a causadora de infecção gastrointestinal e desidratação. ${ }^{17}$ Além disso, várias outras infecções, como as hospitalares, podem ser causadas também por $S$. aureus, sabendo-se que a sua resistência às drogas utilizadas aumenta sua virulência, causando complicações graves, como a pneumonia necrosal e toxicidade neonatal, nos casos de resistência a oxacilina. ${ }^{18}$ Por sua vez, L. monocytogenes, um microorganismo patogênico, também classificado como um problema de saúde pública pelo difícil diagnóstico, pode conduzir à pneumonia, encefalite e meningite adulta e neonatal, sendo de grande risco aos grupos de imunocomprometidos como aidéticos, diabéticos e transplantados. ${ }^{19}$

Os resultados dos ensaios antibacterianos com os extratos, frações e compostos isolados de A. esperanzae dão um suporte científico ao uso da espécie pela população nos casos de infecções/inflamações causadas por artrite reumatoide.

\section{MATERIAL SUPLEMENTAR}

Está disponível em http://quimicanova.sbq.org.br, na forma de arquivo .PDF, com acesso livre. 


\section{AGRADECIMENTOS}

Ao Conselho Nacional de Desenvolvimento Científico e Tecnológico (CNPq), à Fundação Coordenação de Aperfeiçoamento de Pessoal de Nível Superior (CAPES) e Fundação de Amparo à Pesquisa do Estado de Minas Gerais (FAPEMIG) pelo suporte financeiro; além da Profa. Dra. J. Takahashi, Departamento de Química, UFMG, pelas sugestões e comentários.

\section{REFERENCIAS}

1. Hoene, F. C.; Flora Brasílica: Aristolochiaceas 1942, 15, 6.

2. Corrêa, M. P.; Dicionário das plantas úteis do Brasil e das exóticas cultivadas, Imprensa Nacional: Rio de Janeiro, 1978.

3. Stasi, D. C. L.; Plantas Medicinais na Amazônia I, Ed. da UNESP: São Paulo, 1989; Marc, E. B.; Nelly, A.; Annick, D. D.; Frederich, D.; J. Ethnopharmacol. 2008, 120, 315; Adams, M.; Berset, C.; Kessler, M.; Hamburger, M.; J. Ethnopharmacol. 2009, 121, 343; Contrera, A.; Bernardi, A. C.; Pozetti, G. L.; Lopes, R. A.; Contrera, M. G. D.; Rev. Esc. Farm. Odont. 1985, 11, 157.

4. Poon, W. T.; Lai, C. K.; Chan, A. Y. W.; Hong Kong J. Nephrol. 2007, 9 , 7.

5. Meinl, W.; Pabel, U.; Osterloh-Quiroz, M.; Hengstler, J. G.; Glatt, H.; Int. J. Cancer 2006, 118, 1090; Martinez, M. C. M.; Nortier, J.; Vereerstraeten, P.; Vanherweghem, J. -L.; Nephrol Dial. Transplant. 2002, 17, 408; Cheng, C. L.; Chen, K. J.; Shih, P. H.; Lu, L. Y.; Hung, C. F.; Lin, W. C.; Gu, J. Y.; Cancer Lett. 2006, 232, 236.

6. Schindler, H.; Arzneim. Forsch. 1951, 1, 7.

7. Pacheco, A. G.; Oliveira, P. M.; Piló-Veloso, D.; Alcântara, A. F. C.; Molecules 2009, 14, 1245; Wu, K. M.; Farrelly, J. G.; Upton, R.; Chen, J.; Phytomedicine 2007, 14, 273; Palmeira Júnior, S. F.; Conserva, L. M.; Corrêa, M. S. S.; Guilhon, G. M. S. P.; Biochem. Syst. Ecol. 2002, 30, 701; Silva-Brandão, K. L.; Solferini, V. N.; Trigo, J. R.; Biochem. Syst. Ecol. 2006, 34, 291.
8. Lopes, L. M. X; Bolzani, V. S.; Trevisan, L. M. V.; Phytochemistry 1987, 26, 2781; Francisco, C. S.; Messiano, G. B.; Lopes, L. M. X.; Aristeu, T. G.; Oliveira, J. E.; Capellari Jr., L.; Phytochemistry 2008, 69, 168; Wu, T. S.; Damu, A. G.; Su, C. R.; Kuo, P. C.; Nat. Prod. Rep. 2004, 21, 594; Newman, A. A. Em Chemistry of Terpenes and Terpenoids; Connolly, J. D., ed.; Academic Press: London, 1972; Mix, D. B.; Guinaudeau, H.; Shamma, M.; J. Nat. Prod. 1982, 45, 657; Lopes, L. M. X.; Bolzani, V. S.; Phytochemistry 1988, 27, 2265; Lopes, L. M. X.; Bolzani, V. S.; Trevisan, L. M. V.; Rev. Latinoamer. Quim. 1988, 19, 113; Munavalli, S.; Viel, C.; Annales Pharm. Fr. 1969, 27, 449.

9. Jones, W. P.; Kinghorn, A. D. Em Natural Products Isolation; Sarker, S. D.; Latif, Z.; Gray, A. I., eds.; Humana Press Inc.: Totowa, New Jersey, 2006, cap. 13.

10. Costa, H. N. R.; Santos, M. C.; Alcântara, A. F. C.; Silva, M. C.; França, R. C.; Piló-Veloso, D.; Quim. Nova 2008, 31, 744.

11. Agrawal, P. K.; Thakur, R. S.; Magn. Reson. Chem. 1985, 23, 389; Priestap, H. A.; Phytochemistry 1987, 26, 519.

12. Priestap, H. A.; Magn. Reson. Chem. 1989, 27, 460.

13. Pascoli, I. C.; Nascimento, I. R.; Lopes, L. M. X.; Phytochemistry 2006, 67, 735 .

14. Takahashi, J. A.; Pereira, C. R.; Pimenta, L. P. S.; Boaventura, M. A. D.; Silva, L. G. F. E.; Nat. Prod. Res. 2006, 20, 21.

15. Lana, E. J. L.; Carazza, F.; Takahashi, J. A.; J. Agric. Food Chem. 2006, 54, 2053.

16. Agata, N.; Ohta, M.; Yokoyama, K.; Int. J. Food Microbiol. 2002, 73, 23.

17. Kotiranta, A.; Lounatmaa, K. K.; Haapasalo, M. M.; Microbes Infect. 2000, 2, 189.

18. Deurenberg, R. H.; Stobberingh, E. E.; Infect. Genetics Evol. 2008, 8, 747; Mee-Marquet, N. V.; Blanchard, M.; Domelier, A. S.; Quentin, R.; Pathol. Biologie 2004, 52, 579.

19. McLauchlin, J.; Mitchell, R. T.; Smerdon, W. J.; Jewell, K.; Int. J. Food Microbiol. 2004, 92, 15. 


\section{ESTUDO QUÍMICO E ATIVIDADE ANTIBACTERIANA DO CAULE DE Aristolochia esperanzae Kuntze (ARISTOLOCHIACEAE)}

Alison G. Pacheco, Thiago M. Silva, Rozângela M. Manfrini, William S. T. Sallum, Lucienir Pains Duarte, Dorila PilóVeloso e Antônio F. de C. Alcântara*

Departamento de Química, Instituto de Ciências Exatas, Universidade Federal de Minas Gerais, Av. Presidente Antônio Carlos, 6627, 31260-901 Belo Horizonte - MG, Brasil

Vagner F. Knupp

Fundação Centro Tecnológico de Minas Gerais, Av. José Cândido da Silveira, 2000, 31170-000 Belo Horizonte - MG, Brasil

Asarinina (1): p.f. $120,2-121,8^{\circ} \mathrm{C} ; \mathrm{CG} / \mathrm{EM} \mathrm{t}_{\mathrm{R}}=53,916 \mathrm{~min}, \mathrm{~m} / \mathrm{z}$ $354,2[\mathrm{M}]^{+}, 178,0,149,0$ (pico base), 135,1, 131,0 e 77,0; IV ( $v_{\text {máx }} /$ $\left.\mathrm{cm}^{-1}\right) 3090,3025,3010,2950,2910,2890,2835,1650,1630,1610$, $1515,1505,1480,1405,1265,1280,1050,1030,970,775$ e 755 ; $\mathrm{RMN}$ de ${ }^{1} \mathrm{H}\left(400 \mathrm{MHz} ; \mathrm{CDCl}_{3}\right) \delta_{\mathrm{H}} 6,84$ (s; H-2' e H-2"), 6,80 (m; H-6' e H-6"), 6,77 (m; H-5' e H-5"), 5,95 (s; O-CH2-O), 4,82 (d, J = $5,2 \mathrm{~Hz} ; \mathrm{H}-6), 4,39$ (d, $J=7,1 \mathrm{~Hz} ; \mathrm{H}-2), 4,09$ (d, $J=10,2 \mathrm{~Hz} ; \mathrm{H}-4 \beta$ ),

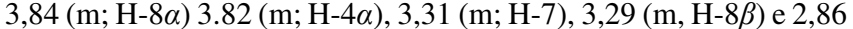
(m; H-3); RMN de ${ }^{13} \mathrm{C}\left(100 \mathrm{MHz} ; \mathrm{CDCl}_{3}\right) \delta_{\mathrm{C}} 148,0$ (C-3"), 147,7 (C-3'), 147,2 (C-4”), 146,6 (C-4'), 135,1 (C-1'), 132,3 (C-1'), 119,6 (C-2”), 118,7 (C-2'), 108,2 (C-5' e C-5”), 106,6 (C-6”), 106,4 (C-6'), 101,1 (O- $\mathrm{CH}_{2}-\mathrm{O}$ '), 100,9 (O-CH $\left.-\mathrm{CH}^{\prime}\right), 87,7$ (C-2), 82,0 (C-6), 70,9 (C-4), 69,7 (C-8), 54,7 (C-3) e 50,2 (C-7).

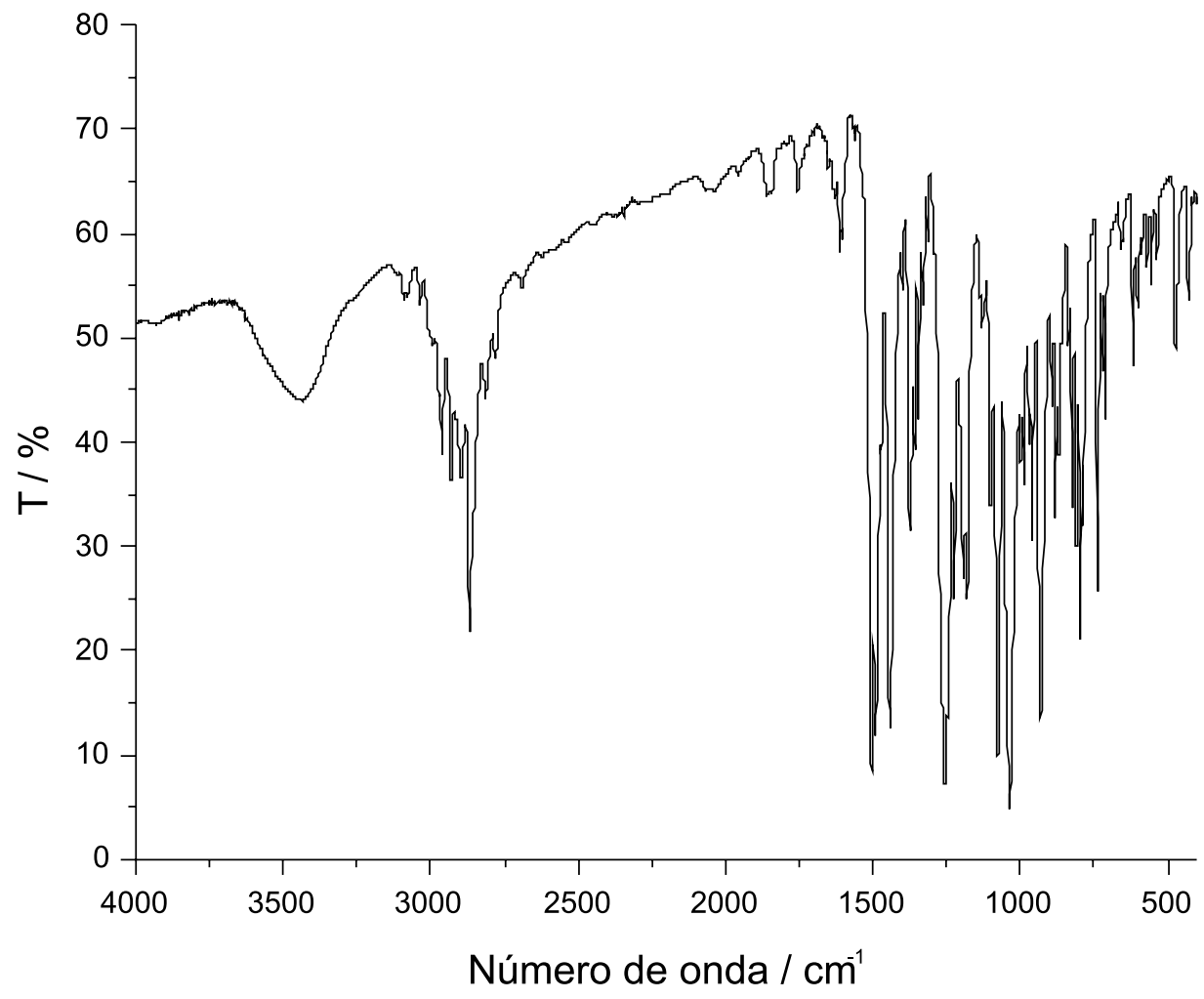

Figura 1S. Espectro de absorção na região do IV de 1 (asarinina; $\mathrm{KBr} ; \mathrm{cm}^{-1}$ )

*e-mail: aalcantara@zeus.qui.ufmg.br 


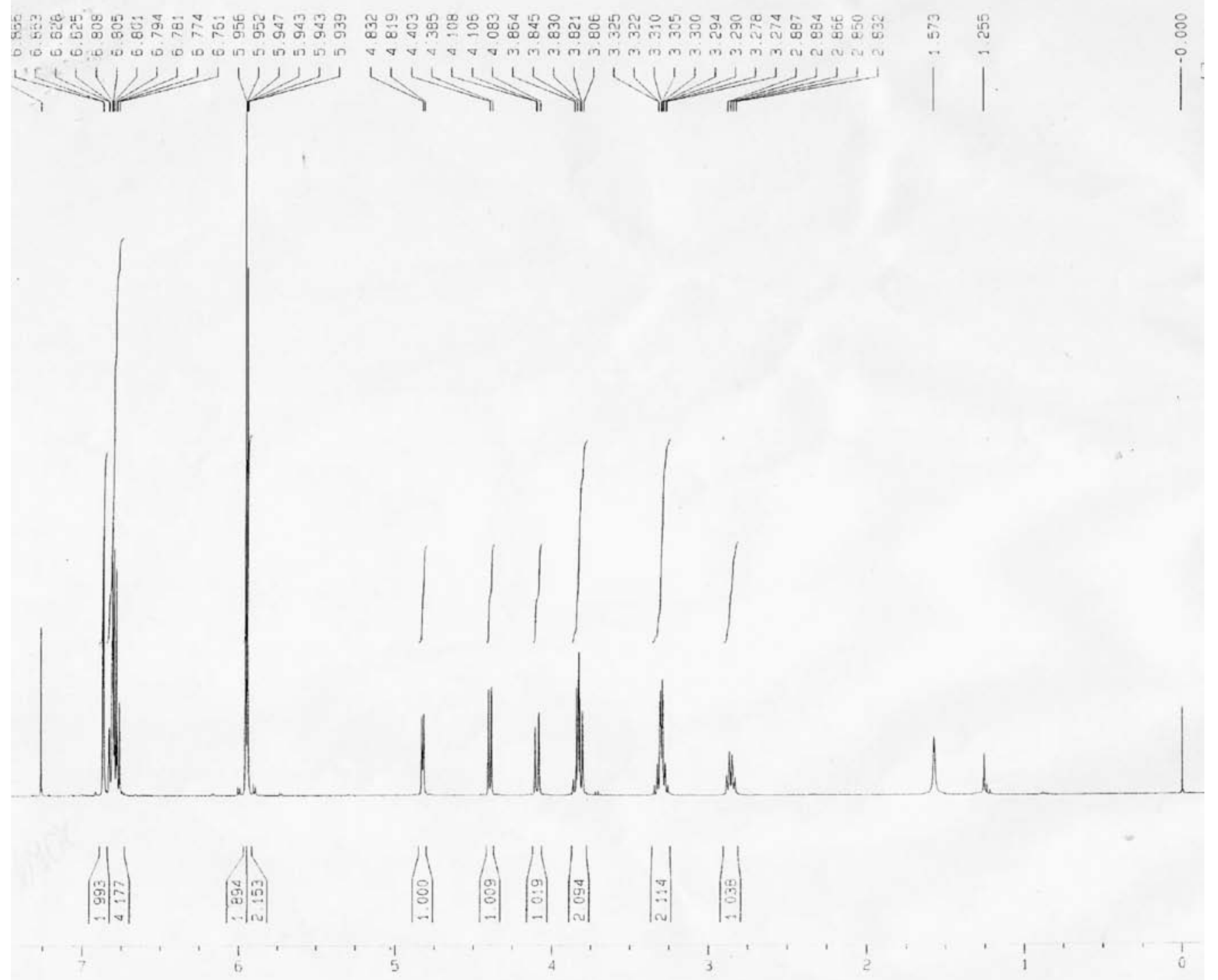

Figura 2S. Espectro de $\mathrm{RMN} \mathrm{de}{ }^{l} \mathrm{H}$ de $\mathbf{1}$ (asarinina; $400 \mathrm{MHz} ; \mathrm{CDCl}_{3}$ ). 


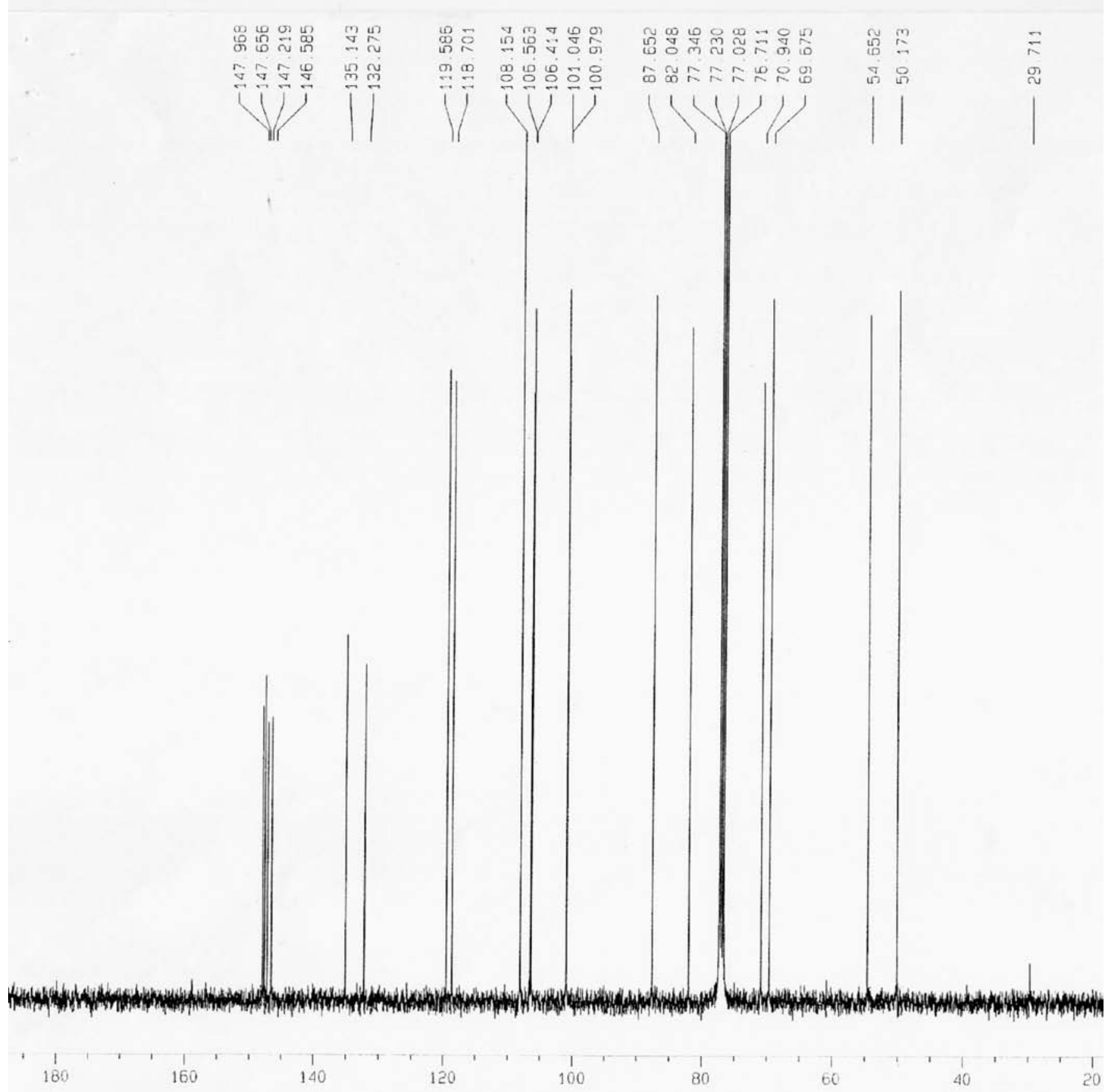

Figura 3S. Espectro de $\mathrm{RMN} \mathrm{de}{ }^{13} \mathrm{C}$ de 1 (asarinina; $100 \mathrm{MHz} ; \mathrm{CDCl}_{3}$ ) 


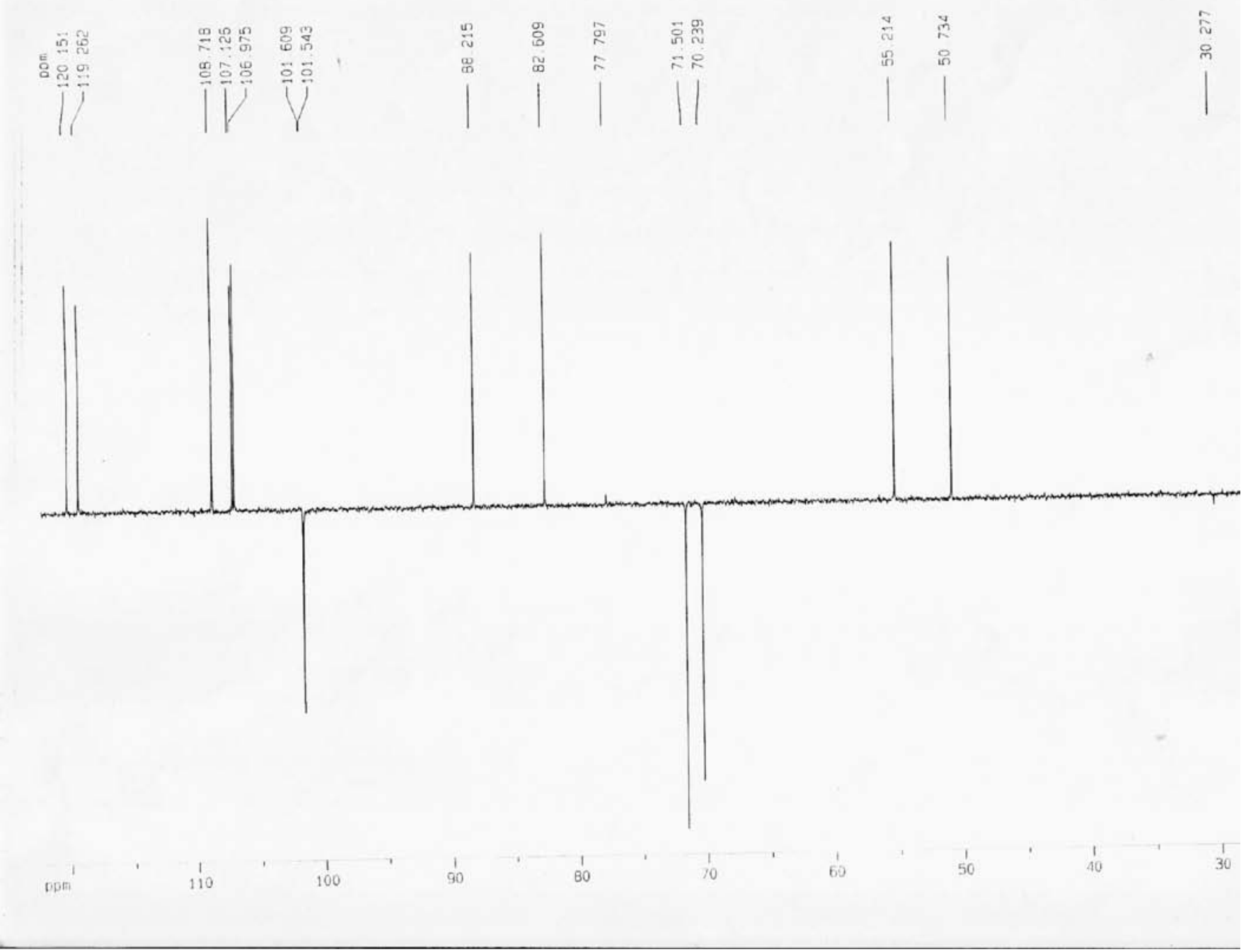

Figura 4S. Subespectro DEPT $135^{\circ}$ de 1 (asarinina; $100 \mathrm{MHz} ; \mathrm{CDCl}_{3}$ ) 

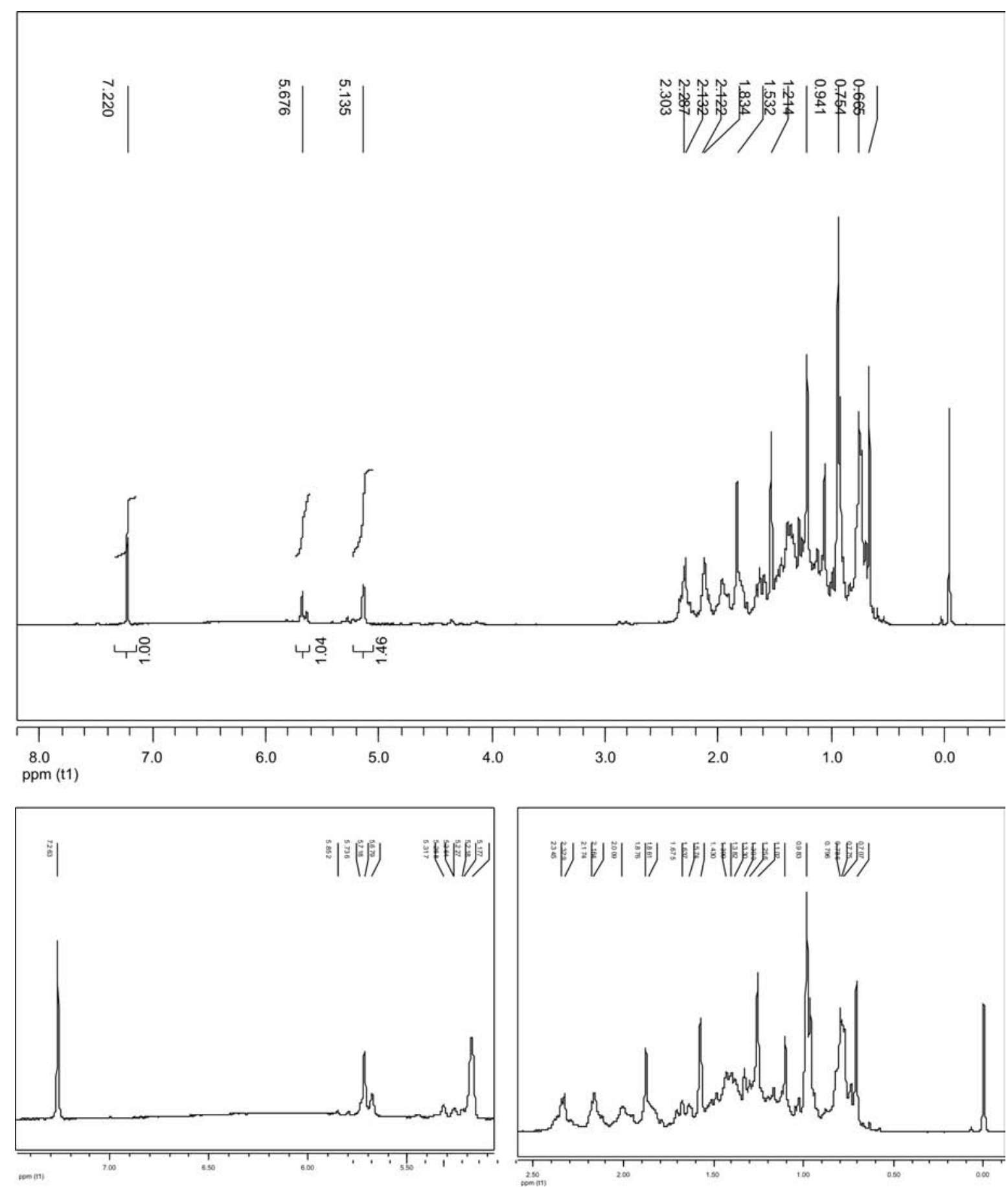

Figura 5S. Espectro de $\mathrm{RMN} \mathrm{de}{ }^{l} \mathrm{H}\left(400 \mathrm{MHz} ; \mathrm{CDCl}_{3}\right.$ ) de mistura dos fitoconstituintes 2 (ácido populifólico) e 3 (ácido 2-oxopopulifólico) (superior) e expansões (inferior) 

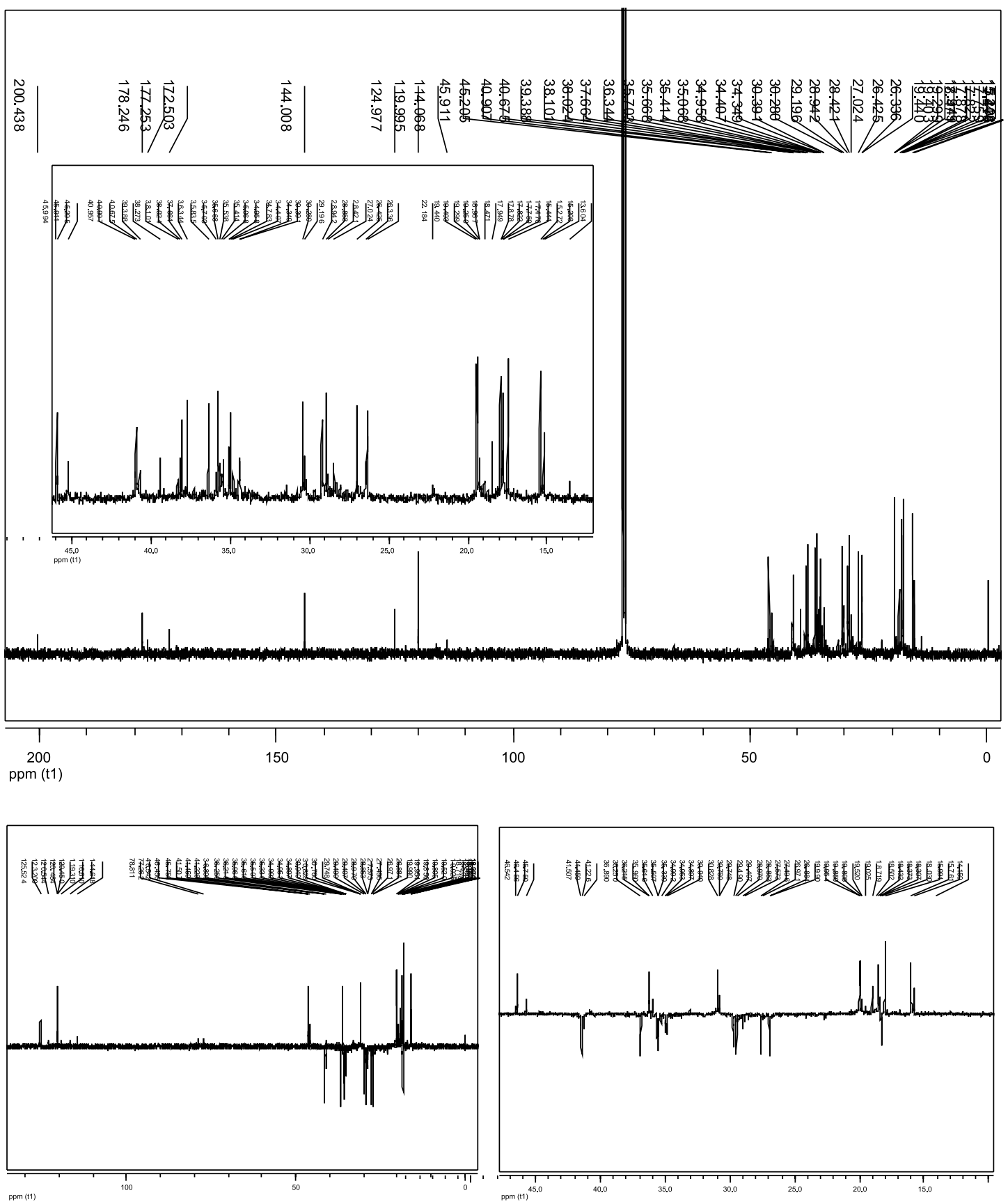

Figura 6S. Espectro de RMN de ${ }^{13} \mathrm{C}$ (superior) e subespectro DEPT $135^{\circ}$ (inferior) de mistura dos fitoconstituintes 2 (ácido populifólico) e 3 (ácido 2-oxopopulifólico $)\left(100 \mathrm{MHz} ; \mathrm{CDCl}_{3}\right)$ 
Ácido aristolóquico II (4): IV $\left(\mathrm{v}_{\text {máx }} / \mathrm{cm}^{-1}\right)$ 3200-2600 (banda larga), $3153,3056,3026,2919,2794,1682,1662,1621,1509,1478,1428$, $1375,1363,1320,1263,1186,1166,1039,1004,944,843$ e 724 ; $\mathrm{RMN}$ de ${ }^{1} \mathrm{H}\left(400 \mathrm{MHz} ; \mathrm{CDCl}_{3}\right) \delta_{\mathrm{H}} 10,79\left(\mathrm{~s} ; \mathrm{CO}_{2} \mathrm{H}\right), 8,51(\mathrm{~d} ; J=8,0$ $\mathrm{Hz}$; H-5), 7,95 (d; $J=7,6$ Hz; H-8), 7,62 (s; H-2), 7,59-7,55 (m; H-6 e H-7); 7,12 (s; H-9) e 6,48 (s; O- $\left.\mathrm{CH}_{2}-\mathrm{O}\right)$; $\mathrm{RMN}$ de ${ }^{13} \mathrm{C}(100 \mathrm{MHz}$;
$\left.\mathrm{CDCl}_{3}\right) \delta_{\mathrm{C}} 168,0\left(\mathrm{CO}_{2} \mathrm{H}\right), 148,7(\mathrm{C}-3), 146,7$ (C-4), 135,0 (C-10), 133,9 (C-10a), 128,6 (C-8), 127,4 (C-6), 126,2 (C-5), 125,1 (C-7), 125,0 (C-4b), 123,8 (C-8a), 119,1 (C-1), 110,8 (C-4a), 105,1 (C-2), $104,2$ (C-9) e 103,1 (O-CH $-\mathrm{O})$; CG/EM t $\mathrm{R}_{\mathrm{R}}=53,304 \mathrm{~min}, \mathrm{~m} / \mathrm{z}, 264,1$ $\left[\mathrm{M}-\mathrm{NO}_{2}\right]^{+}, 263,2$ (pico base), 237,2, 236,1, 208,9, 207,8, 178,2, $152,6,151,2$ e 131,1 .

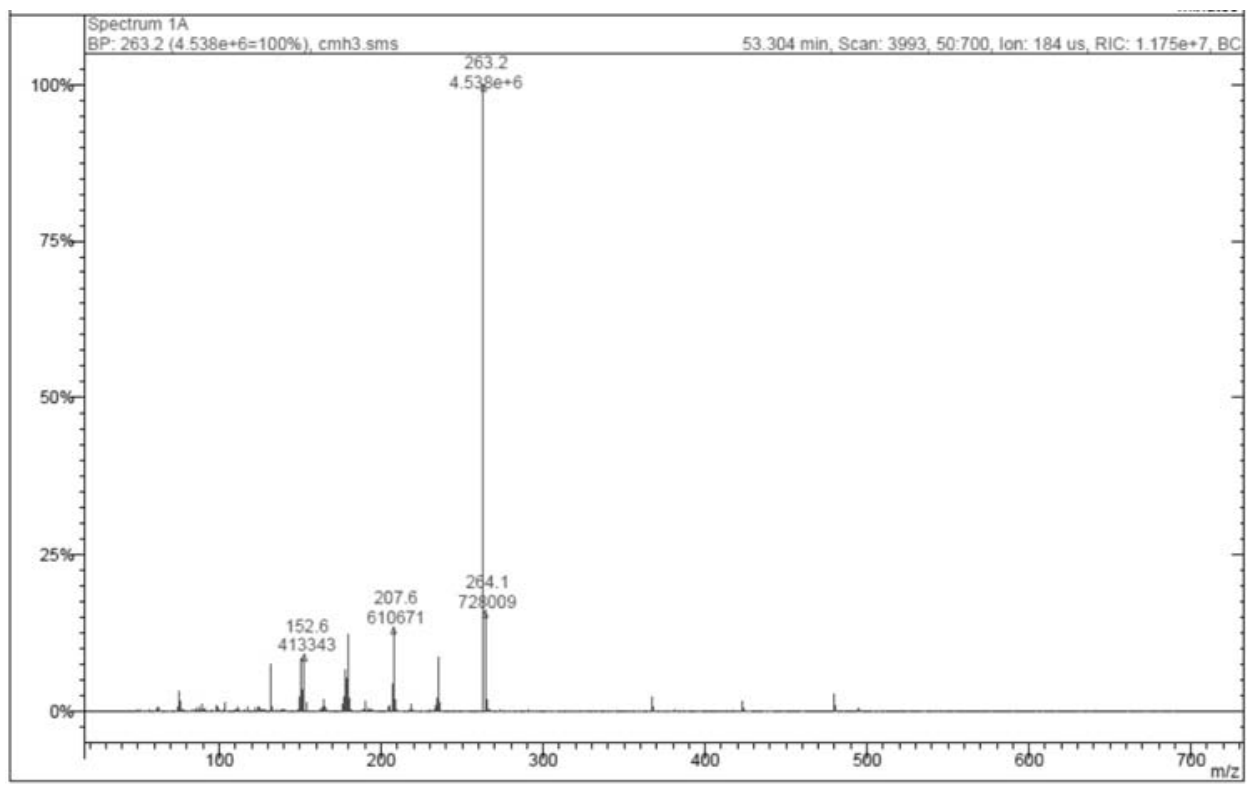

Figura 7S. Espectro de massas de $\mathbf{4}$ (ácido aristolóquico II)

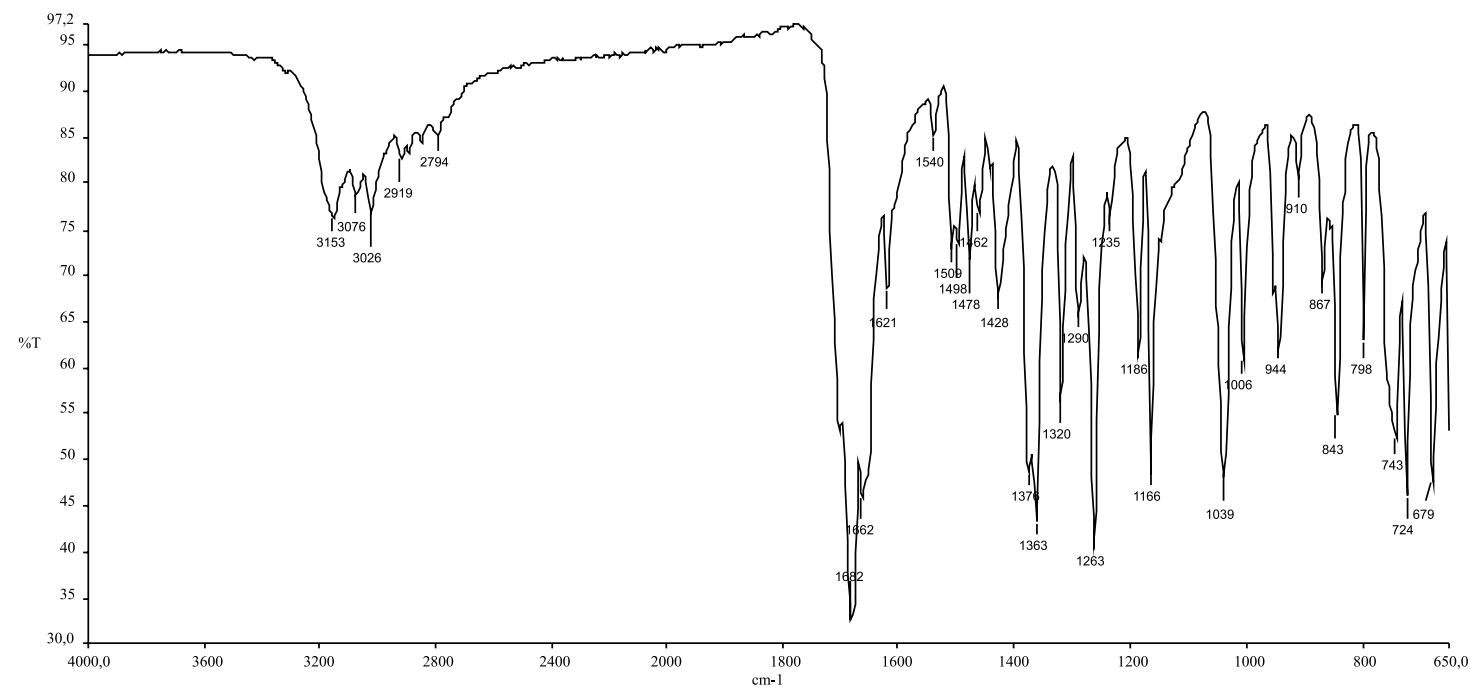

Figura 8S. Espectro de absorção na região do IV de 4 (ácido aristolóquico II; $\mathrm{KBr} ; \mathrm{cm}^{-1}$ ) 

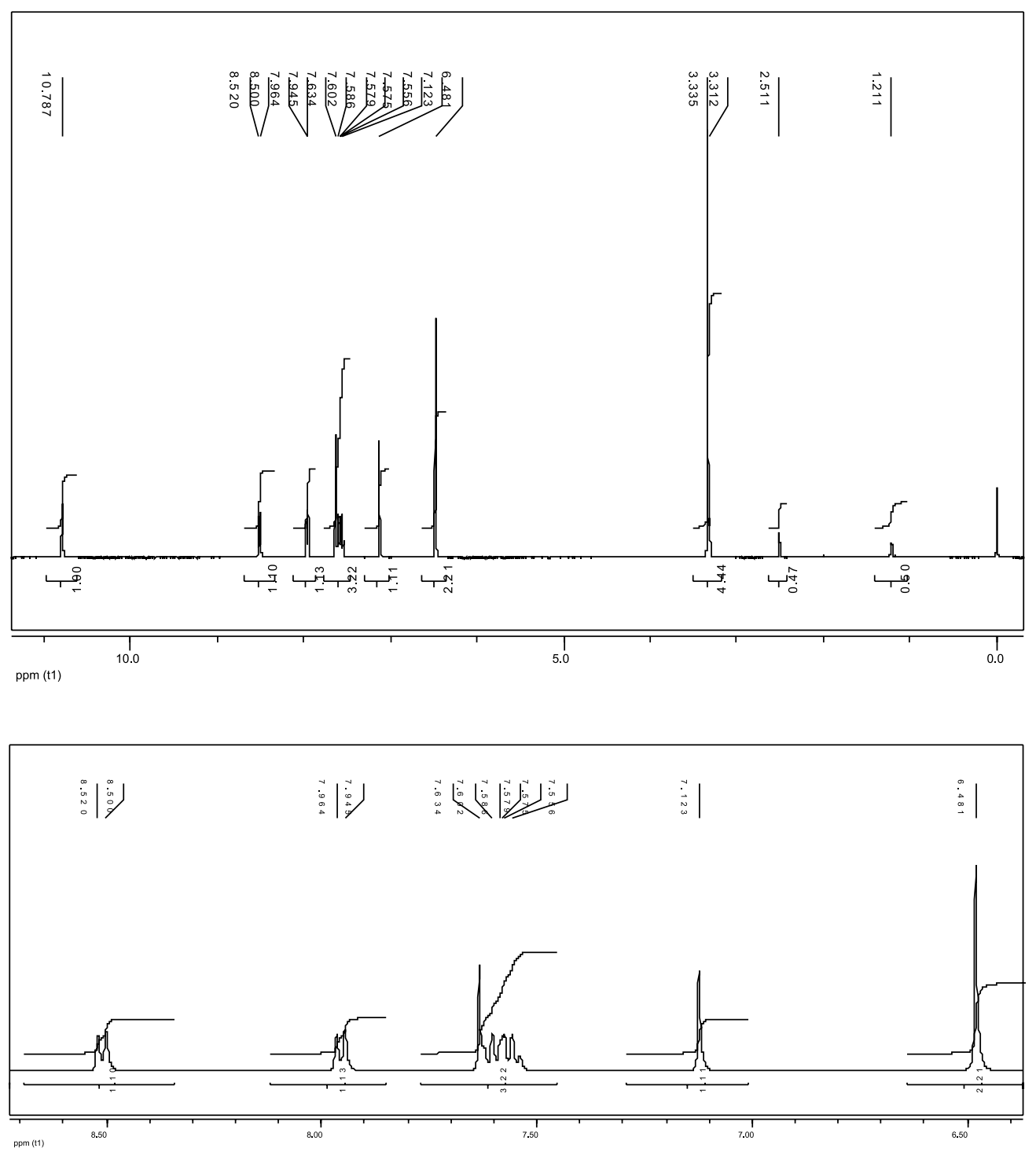

Figura 9S. Espectro de RMN de ${ }^{l} \mathrm{H}$ de 4 (ácido aristolóquico II) e expansão correspondente (400 MHz; DMSO-d $)$ 


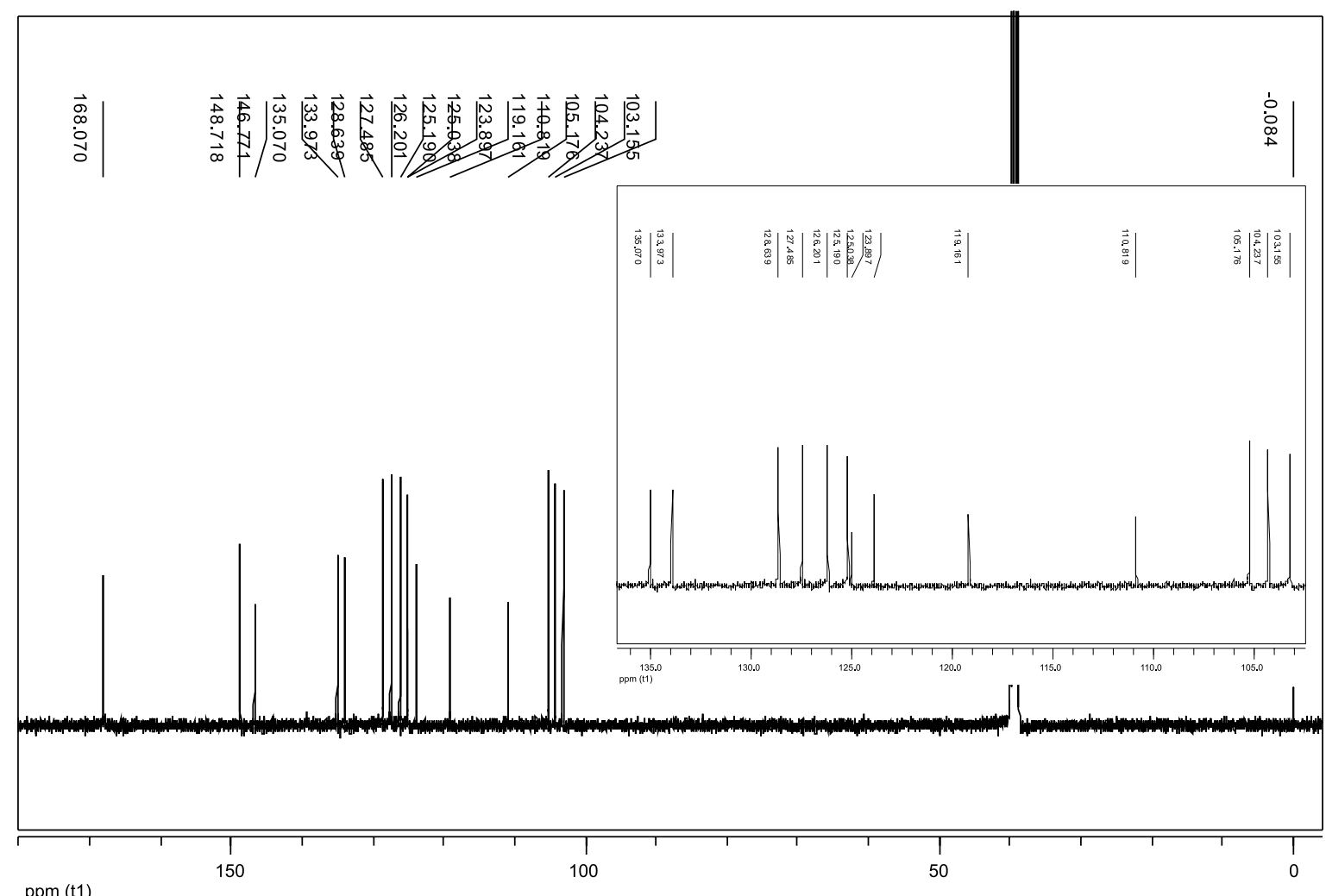

ppm (t1)

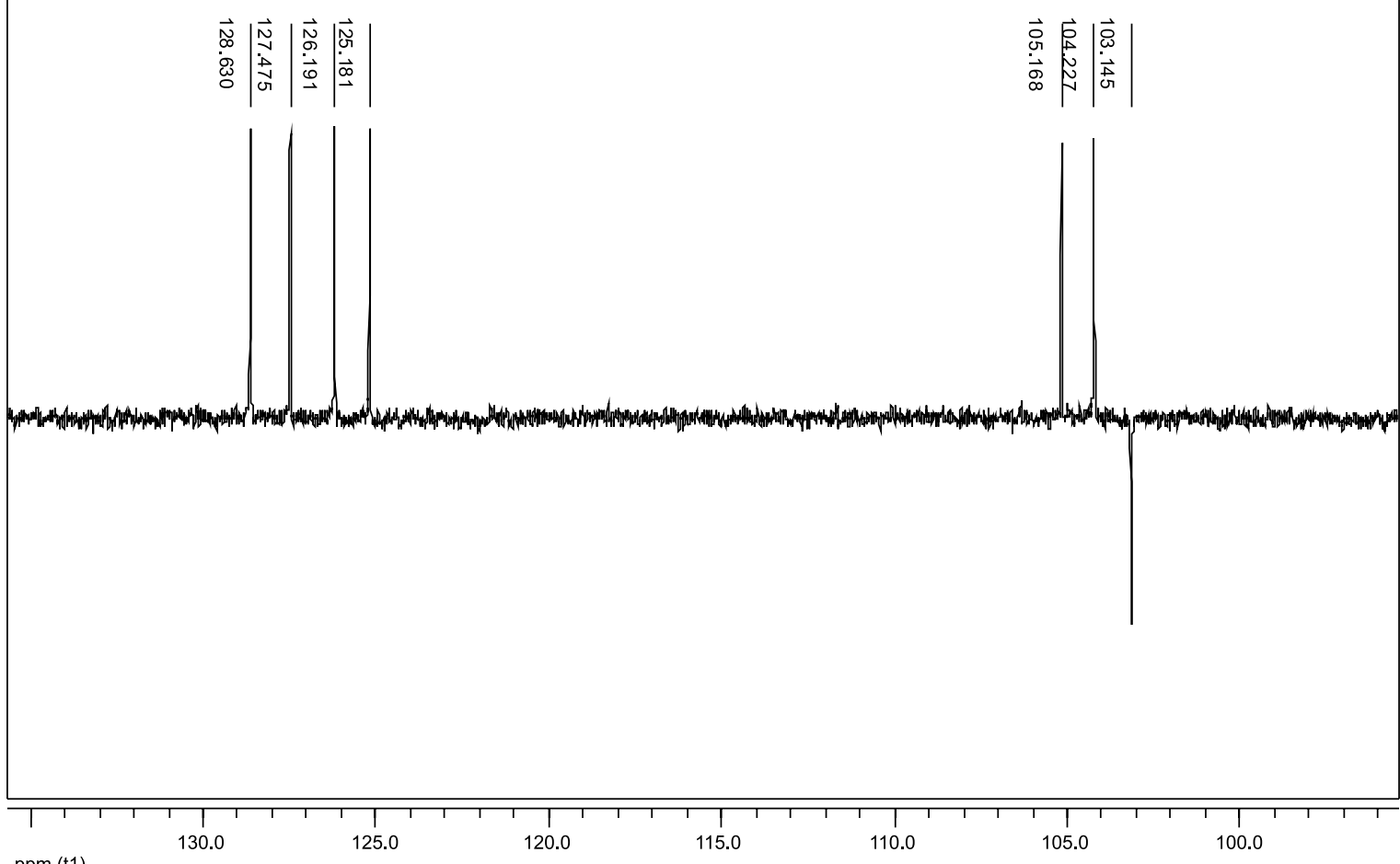

ppm (t1)

Figura 10S. Espectro de RMN de ${ }^{13} \mathrm{C}$ (superior) e subespectro DEPT $135^{\circ}$ (inferior) de 4 (ácido aristolóquico II; $100 \mathrm{MHz}$; DMSO-d ) 
Aristolactama AII (5): IV ( $\left.v_{\text {máx }} / \mathrm{cm}^{-1}\right)$ 3300-2750 (banda larga), 3255, 3194, 2979, 1699, 1624, 1500, 1422, 1355, 1328, 1292, 1241, 1181, 1153, 1124, 1096, 1056, 1033, 984, 905, 875, 848, 803 e 753; RMN de ${ }^{1} \mathrm{H}\left(400 \mathrm{MHz} ; \mathrm{CDCl}_{3}\right) \delta_{\mathrm{H}} 10,66(\mathrm{~s} ; \mathrm{NH}), 10,14(\mathrm{~s} ; \mathrm{OH})$, 9,15 (d; $J=8,8 \mathrm{~Hz}$; H-5), 7,86 (d; $J=7,6 \mathrm{~Hz} ; \mathrm{H}-8), 7,66$ (s; H-2), 7,57-7,50 (m; H-6 e H-7), 7,06 (s; H-9) e 4,07 (s; $\mathrm{CH}_{3} \mathrm{O}$ ); $\mathrm{RMN}$ de
${ }^{13} \mathrm{C}\left(100 \mathrm{MHz} ; \mathrm{CDCl}_{3}\right) \delta_{\mathrm{C}} 168,5(\mathrm{HNC}=\mathrm{O}), 151,9(\mathrm{C}-3), 148,6(\mathrm{C}-4)$, 135,2 (C-10), 134,6 (C-8a), 128,5 (C-8), 126,8 (C-7), 126,6 (C-5), 126,0 (C-4b), 124,8 (C-6), 122,4 (C-10a), 121,7 (C-1), 120,3 (C-4a), $113,3(\mathrm{C}-2), 103,6(\mathrm{C}-9)$ e $59,2\left(\mathrm{CH}_{3} \mathrm{O}\right) ; \mathrm{CG} / \mathrm{EM} \mathrm{t}_{\mathrm{R}}=53,770 \mathrm{~min}, \mathrm{~m} / \mathrm{z}$ $266,3[\mathrm{M}+1]^{+}, 265,4[\mathrm{M}]^{+}$(pico base), 250,6, 222,6, 166,6 e 139,6.

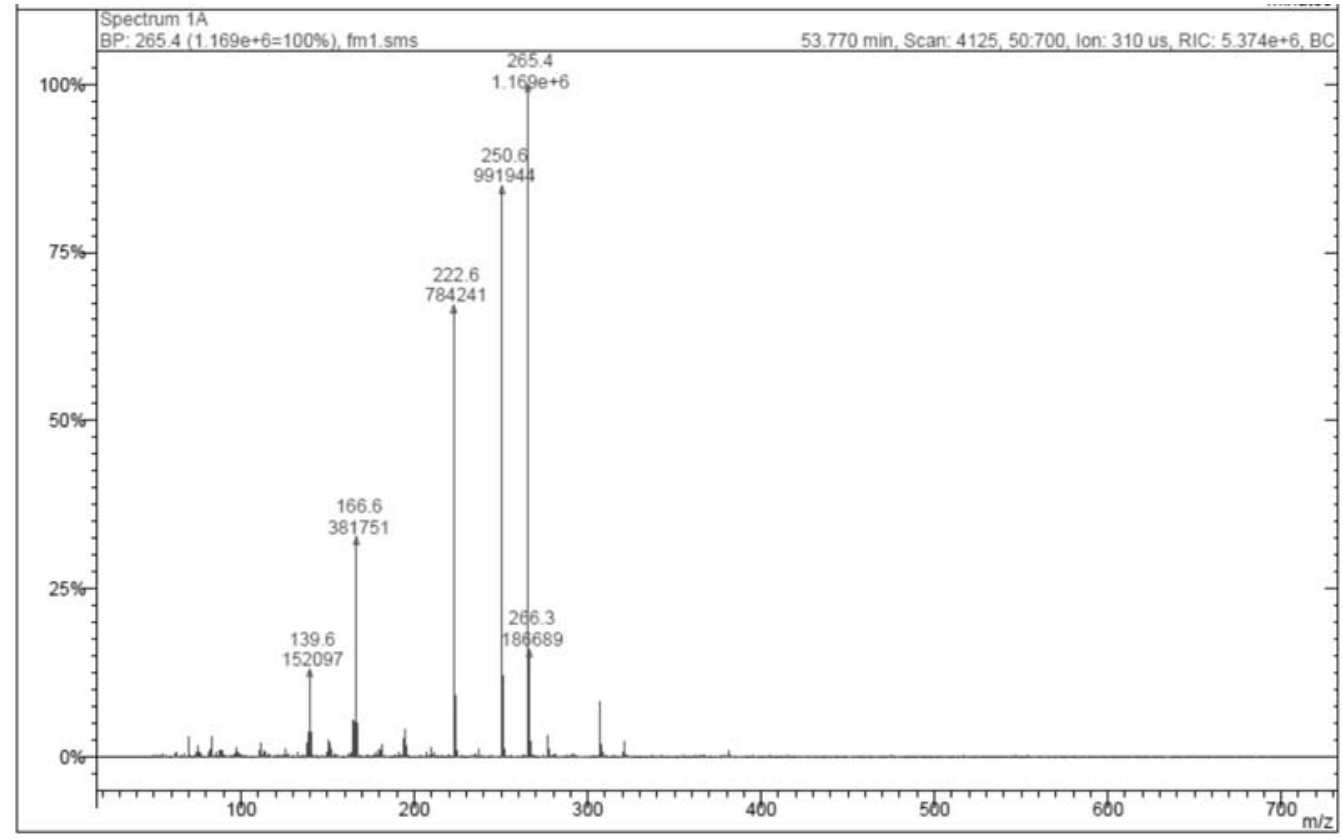

Figura 11S. Espectro de massas de 5 (aristolactama AII)

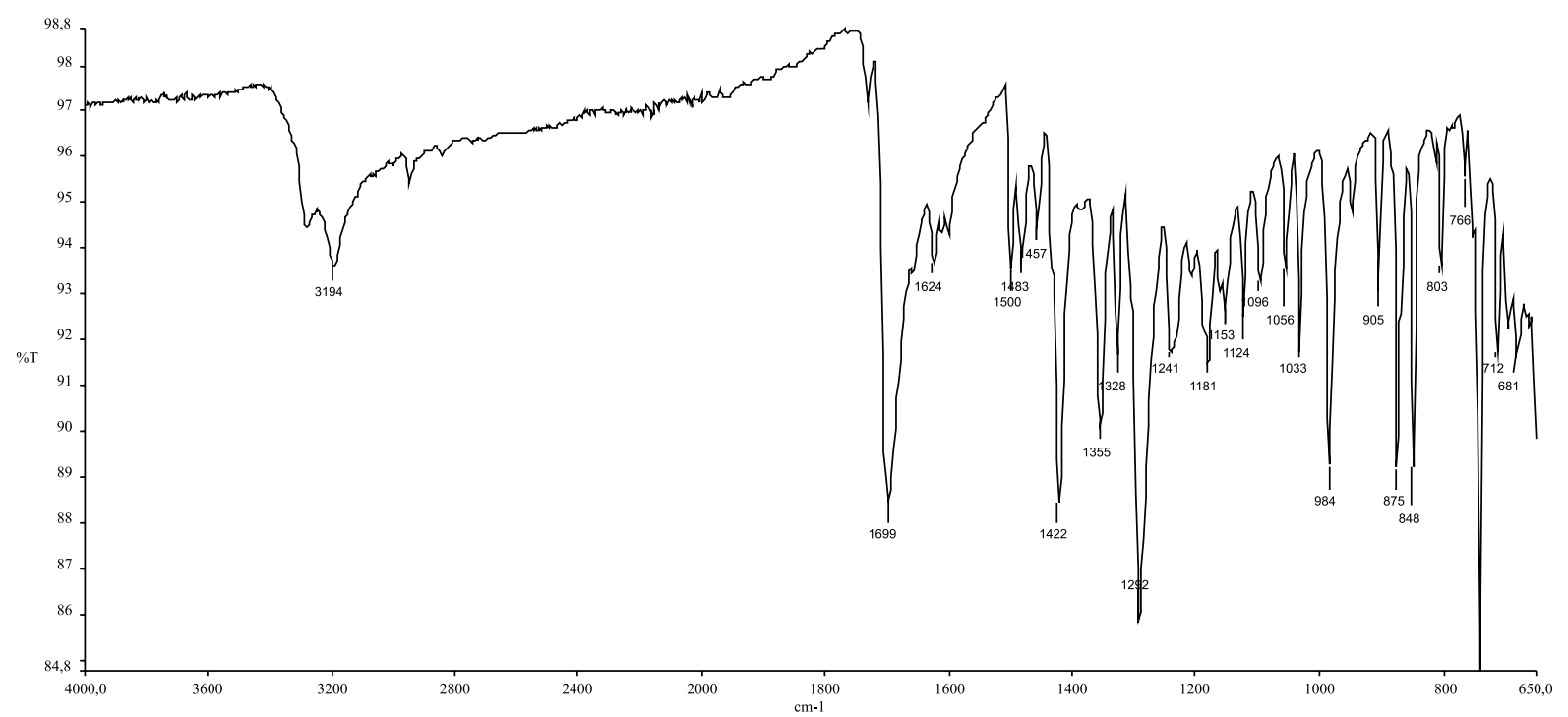

Figura 12S. Espectro de absorção na região do IV de 5 (aristolactama AII; $\mathrm{KBr} ; \mathrm{cm}^{-1}$ ) 


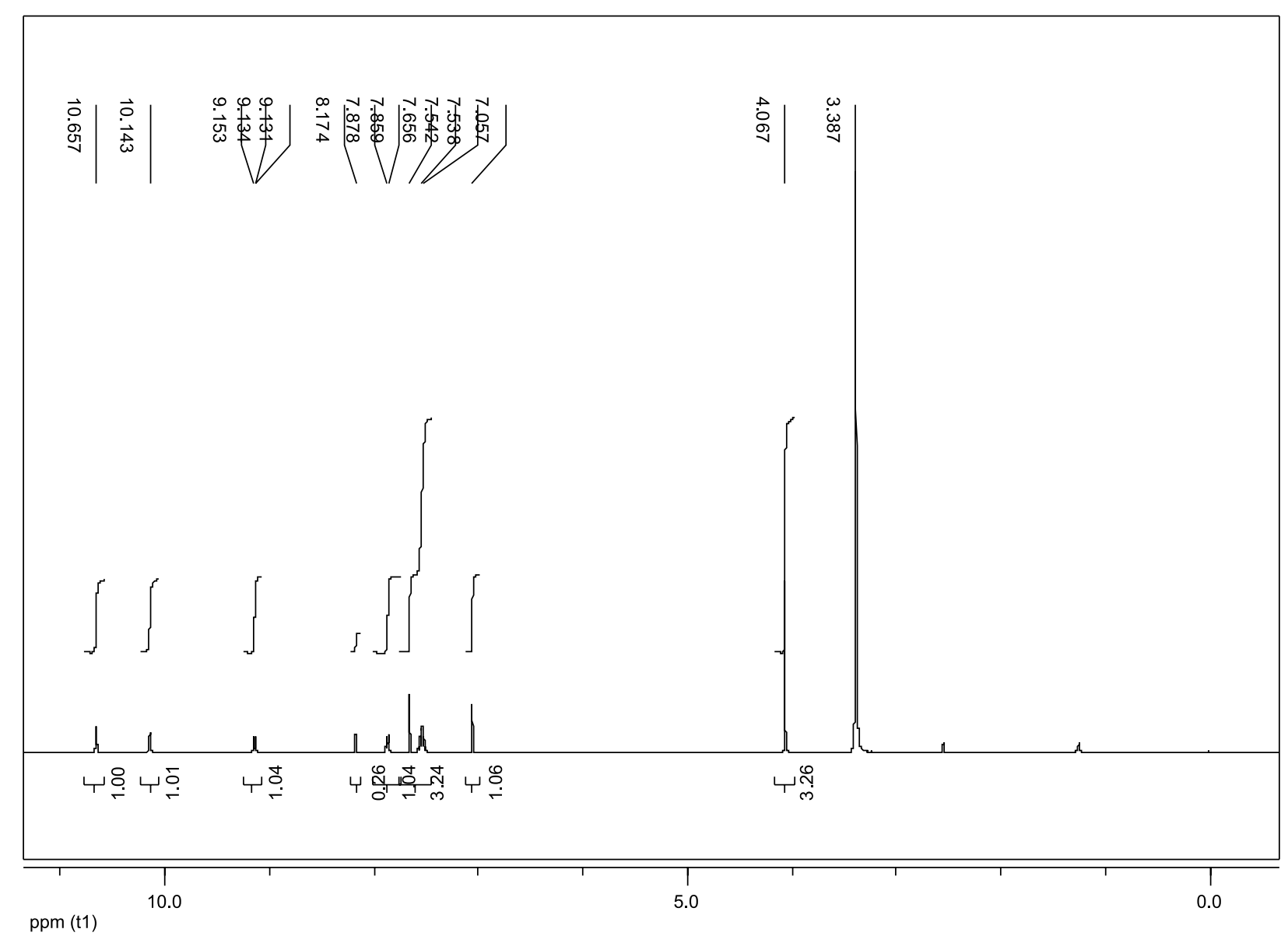

Figura 13S. Espectro de RMN de ${ }^{l} \mathrm{H}$ de 5 (aristolactama AII; $400 \mathrm{MHz}$; DMSO-d $)$ 

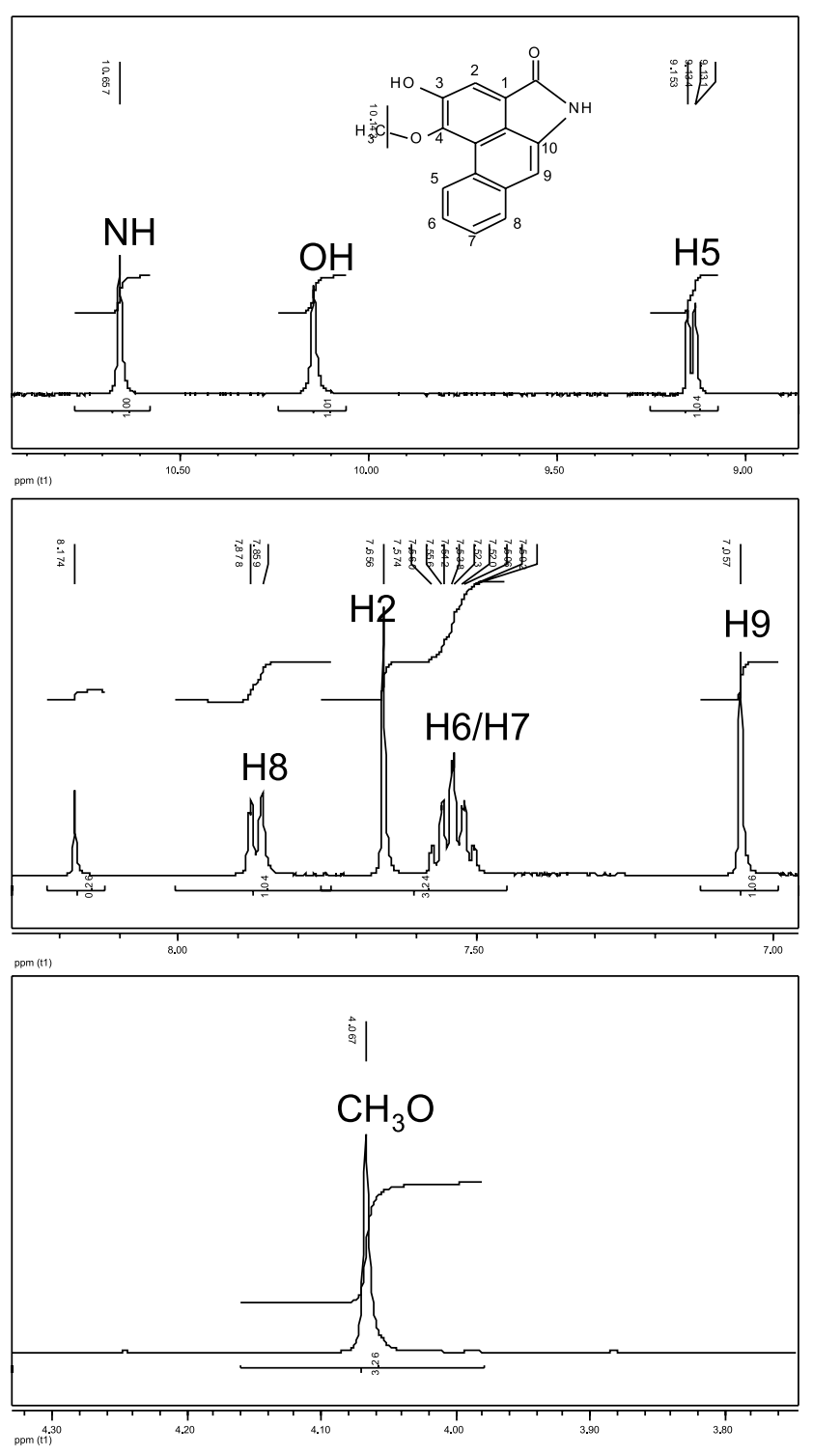

Figura 14S. Expansões do espectro de RMN de ${ }^{l} \mathrm{H}$ de 5 (aristolactama AII; $400 \mathrm{MHz}$; DMSO-d ${ }_{6}$ ) 


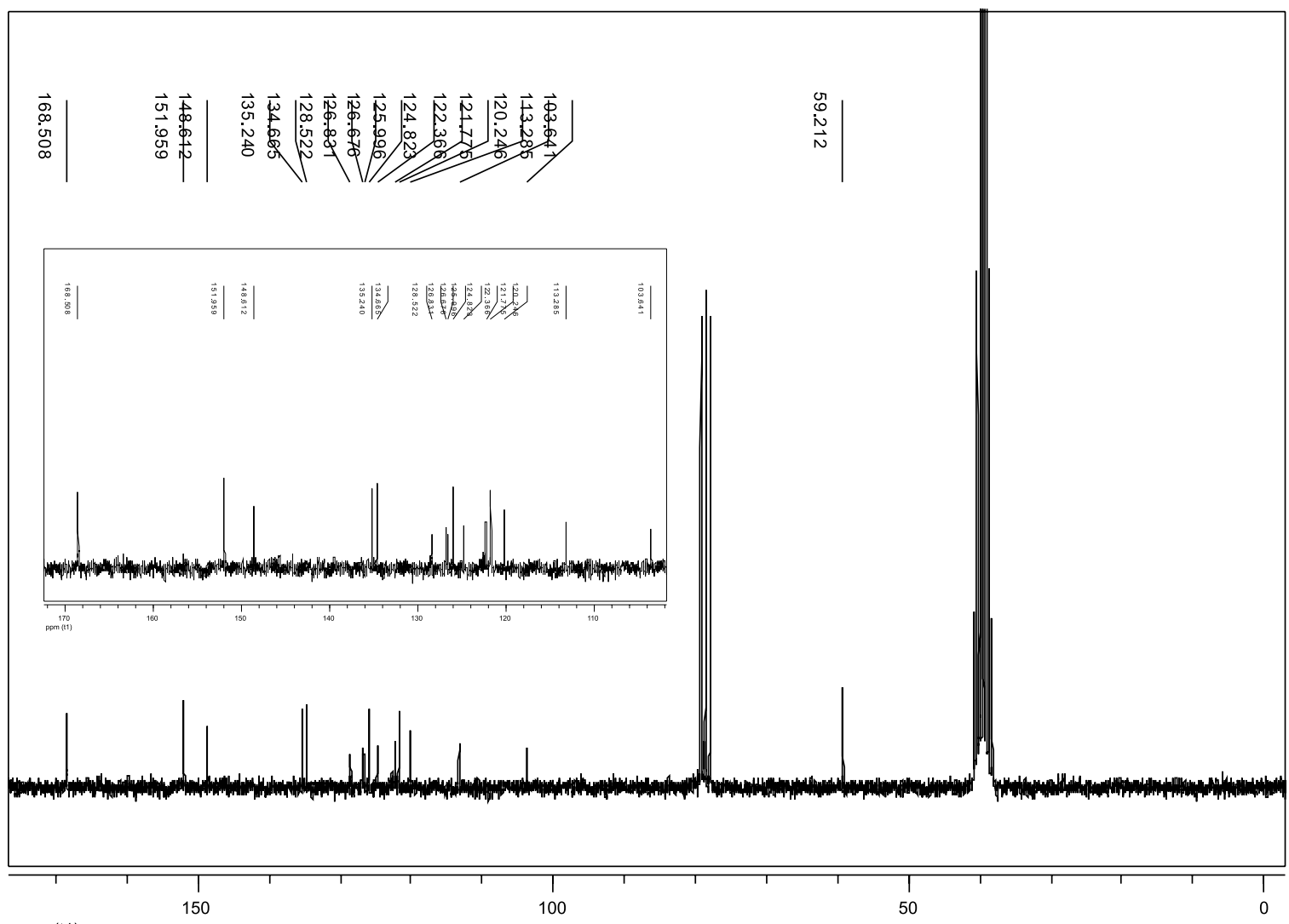

$\operatorname{ppm}(\mathrm{t} 1)$
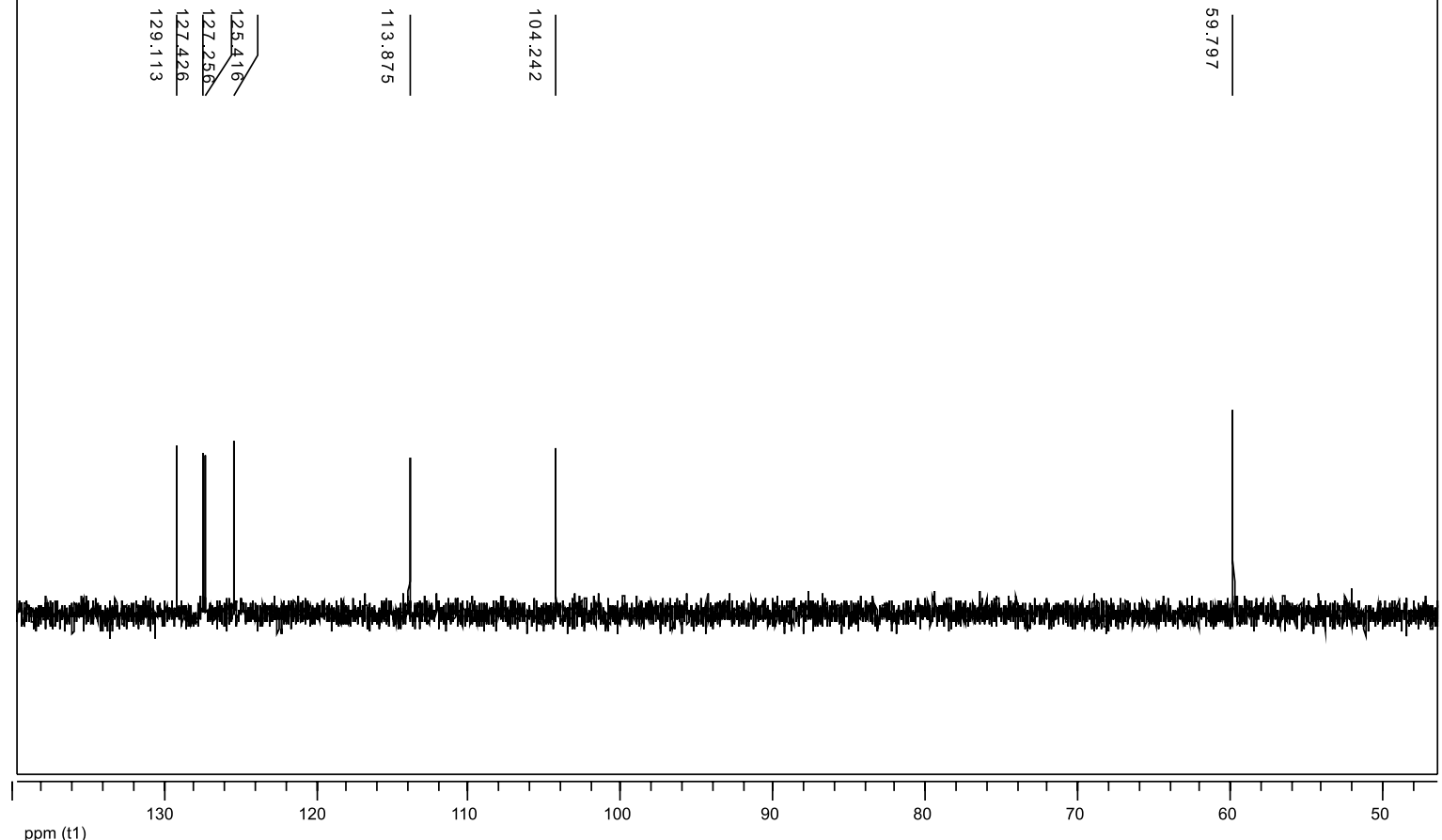

Figura 15S. Espectro de RMN de ${ }^{13} \mathrm{C}$ (superior) e subespectro DEPT $135^{\circ}$ (inferior) de 5 (aristolactama AII; $100 \mathrm{MHz}$; DMSO-d ) $^{2}$ 
Aristolactama AIa (6): IV ( $\left.v_{\text {máx }} / \mathrm{cm}^{-1}\right)$ 3300-2750 (banda larga), 3255, 3197, 2977, 1690, 1619, 1503, 1422, 1355, 1328, 1292, 1240, 1181, 1153, 1124, 1104, 1055, 1037, 984, 901, 868, 846, 803 e 755; RMN de ${ }^{1} \mathrm{H}\left(400 \mathrm{MHz} ; \mathrm{CDCl}_{3}\right) \delta_{\mathrm{H}} 10,49(\mathrm{~s} ; \mathrm{NH}), 9,89(\mathrm{~s} ; \mathrm{C}-3-\mathrm{OH})$, 9,10 (d, J=9,2 Hz; H-5), 7,90 (s; C-8-OH), 7,80 (d, J= 7,2 Hz; H-7),
7,67 (s; H-2), 7,51 (dd, $J=9,2$ e 7,2 Hz; H-6), 7,01 (s; H-9) e 4,07 (s; $\left.\mathrm{CH}_{3} \mathrm{O}\right) ; \mathrm{RMN}$ de ${ }^{13} \mathrm{C}\left(100 \mathrm{MHz} ; \mathrm{CDCl}_{3}\right) \delta_{\mathrm{C}} 167,6(\mathrm{C}=\mathrm{O}), 150,7$ (C-3), 147,4 (C-4), 134,1 (C-8a e C-10), 133,4 (C-8), 127,2 (C-7), 125,6 (C-5), 124,9 (C-4b), 123,6 (C-6), 121,4 (C-10a), 120,7 (C-1), 119,1 (C-4a), 112,2 (C-2), 102,5 (C-9) e 58,1 ( $\left.\mathrm{CH}_{3} \mathrm{O}\right)$.

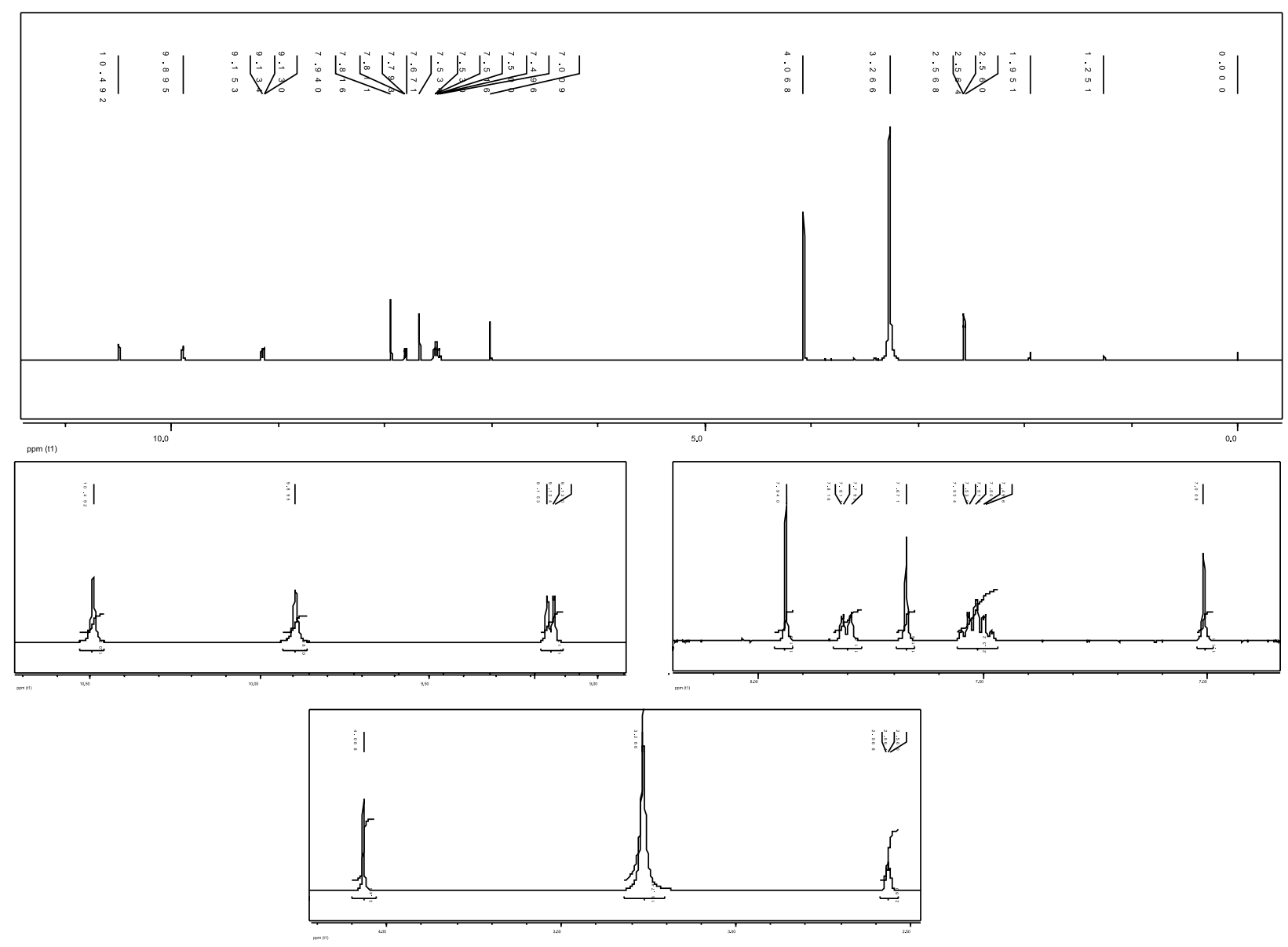

Figura 16S. Espectro de $\mathrm{RMN}$ de ${ }^{l} \mathrm{H}$ de 6 e expansões correspondentes (aristolactama AIa; $400 \mathrm{MHz} ; \mathrm{CDCl}_{3}$ ) 


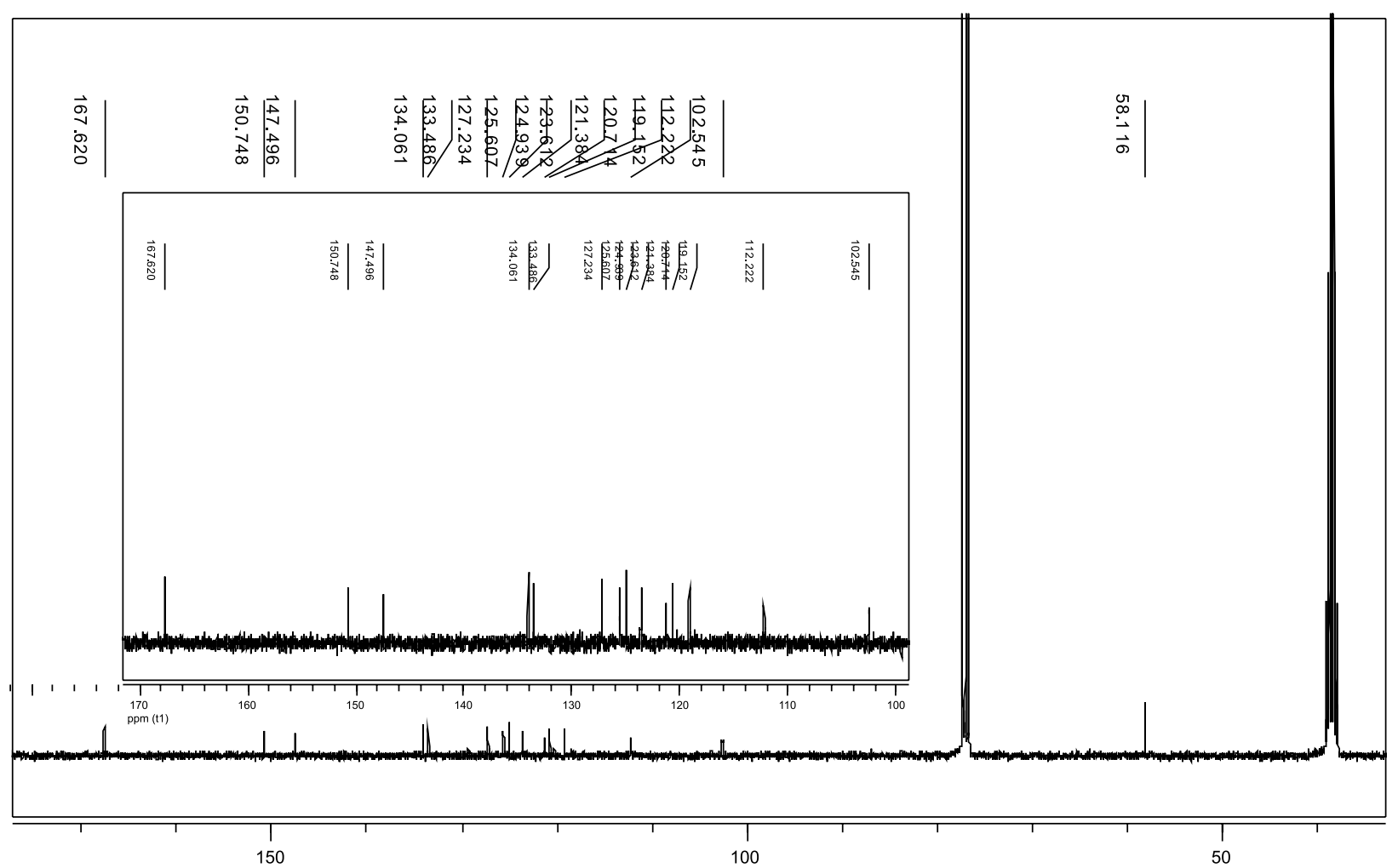

$\operatorname{ppm}(\mathrm{t} 1)$

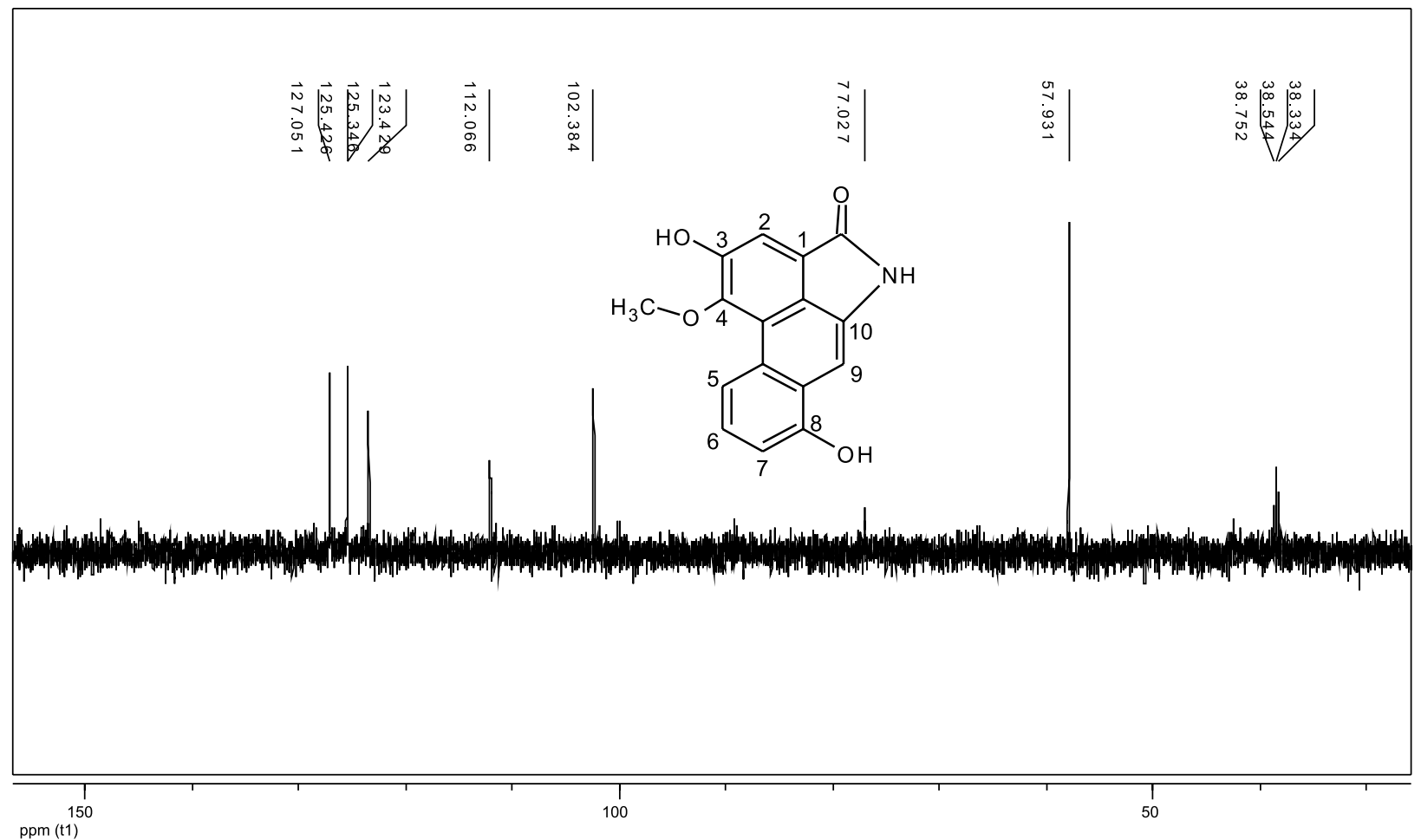

Figura 17S. Espectro de RMN de ${ }^{13} \mathrm{C}$ (superior) e subespectro DEPT $135^{\circ}$ (inferior) de 6 e expansões correspondentes (aristolactama AIa; $100 \mathrm{MHz}$; CDCl $\left.{ }_{3}\right)$ 
$\beta$-Cubebina (7): p.f. $122,7-128,0{ }^{\circ} \mathrm{C}$; IV $\left(v_{\text {máx }} / \mathrm{cm}^{-1}\right) 3332$ (banda larga), 2948, 2926, 2897, 2781, 1608, 1495, 1484, 1439, 1365, 1356, 1238, 1185, 1118, 1096, 1037, 1006, 922 e 807; RMN de ${ }^{1} \mathrm{H}(400$ $\left.\mathrm{MHz} ; \mathrm{CDCl}_{3}\right) \delta_{\mathrm{H}} 6,67$ (s; H-2'), 6,66 (m; H-5 e H-5'), 6,62 (m; H-6'), 6,56 (m; H-2), 6,52 (m; H-6), 5,87 (s; O-CH $-\mathrm{O}), 5,85$ (s; O- $\left.\mathrm{CH}_{2}-\mathrm{O}^{\prime}\right)$, 5,15 (d, $J=13,2$ Hz; H-9), 4,03 (dd, $J=8,4$ e 4,3 Hz; H-9' $\beta$ ), 3,50 (dd, $J=8,4$ e 6,1; H-9' $\alpha$ ), 2,90 (m; H-7a), 2,86 (sl; OH), 2,70 (m;
H-7'a), 2,62 (m; H-7b), 2,50 (m; H-7'b), 2,37 (m; H-8') e 1,93 (m; $\mathrm{H}-8)$; RMN de ${ }^{13} \mathrm{C}\left(100 \mathrm{MHz} ; \mathrm{CDCl}_{3}\right) \delta_{\mathrm{C}} 147,7$ (C-3), 147,5 (C-3'), 145,9 (C-4'), 145,7 (C-4), 134,5 (C-1'), 133,8 (C-1), 121,6 (C-6'), 121,3 (C-6), 109,3 (C-2'), 108,9 (C-2), 108,2 (C-5), 108,1 (C-5'), $108,8\left(\mathrm{O}-\mathrm{CH}_{2}-\mathrm{O}\right.$ e O-CH$-\mathrm{C}_{2}$ ), 98,8 (C-9), 72,5 (C-9'), 51,9 (C-8), 42,9 (C-8'), 38,8 (C-7') e 33,6(C-7).

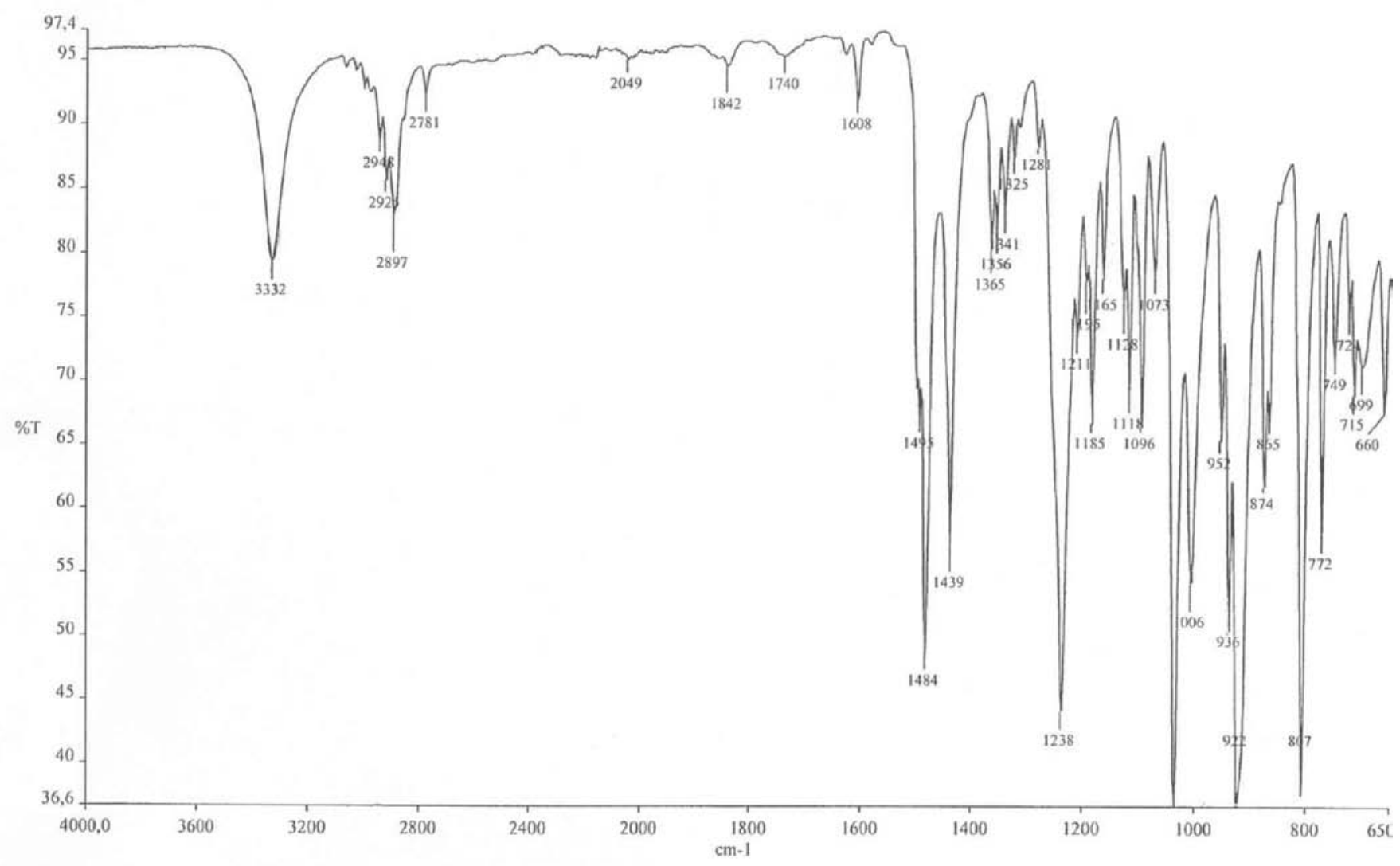

Figura 18S. Espectro de absorção na região do IV de 7 ( $\beta$-cubebina; $\left.\mathrm{KBr} ; \mathrm{cm}^{-1}\right)$ 

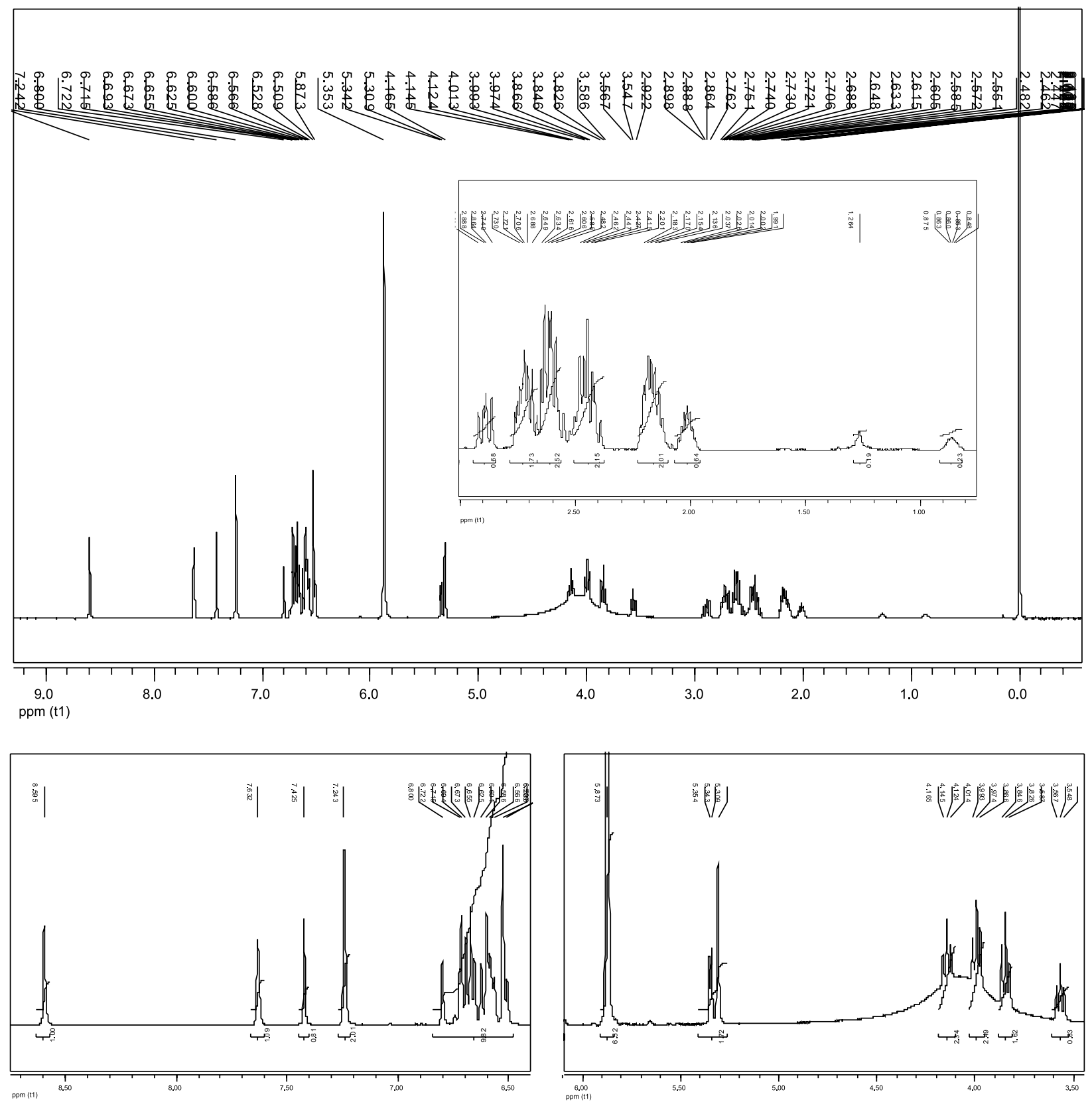

Figura 19S. Espectro de $\mathrm{RMN}$ de ${ }^{l} \mathrm{H}$ de 7 ( $\beta$-cubebina; $400 \mathrm{MHz} ; \mathrm{CDCl}_{3}$ ) 

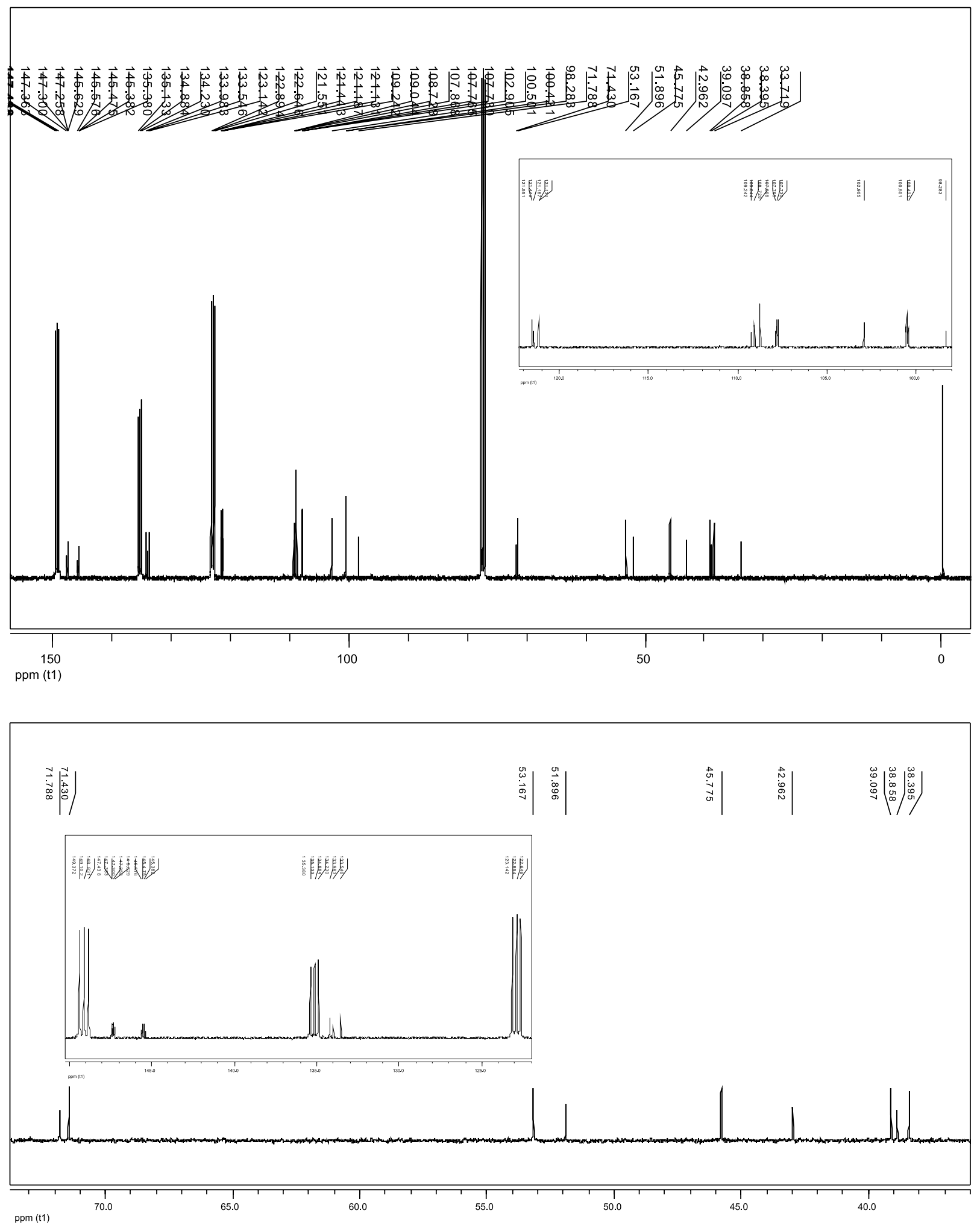

Figura 20S. Espectro de $\mathrm{RMN}$ de ${ }^{13} \mathrm{C}$ de 7 e expansões ( $\beta$-cubebina; $100 \mathrm{MHz} ; \mathrm{CDCl}_{3}$ com gotas de piridina) 
Ácido aristolóquico I (8): IV $\left(v_{\text {máx }} / \mathrm{cm}^{-1}\right)$ 3200-2600 (banda larga), $1684,1622,1593,1524,1504,1468,1448,1416,1370,1345,1265$, 1247, 1147, 1115, 1039, 997, 945, 921, 900, 803 e 722; RMN de ${ }^{1} \mathrm{H}$ $\left(400 \mathrm{MHz} ; \mathrm{CDCl}_{3}\right) \delta_{\mathrm{H}} 13,32\left(\mathrm{sl} ; \mathrm{CO}_{2} \mathrm{H}\right), 8,61(\mathrm{~d}, J=8,4 \mathrm{~Hz} ; \mathrm{H}-5)$, $8,56$ (s; H-9), 7,83 (t, $J=8,4 \mathrm{~Hz} ; \mathrm{H}-6), 7,80$ (s; H-2), 7,34 (d, $J=$ $8,4 \mathrm{~Hz} ; \mathrm{H}-7), 6,48\left(\mathrm{~s} ; \mathrm{O}-\mathrm{CH}_{2}-\mathrm{O}\right)$ e $4,05\left(\mathrm{~s} ; \mathrm{OCH}_{3}\right) ; \mathrm{RMN}$ de ${ }^{13} \mathrm{C}(100$
$\left.\mathrm{MHz} ; \mathrm{CDCl}_{3}\right) \delta_{\mathrm{C}} 167,5\left(\mathrm{CO}_{2} \mathrm{H}\right), 156,1$ (C-8), 146,4 (C-10), 145,9 (C-3), 145,6 (C-4), 131,4 (C-6), 129,7 (C-10a), 124,0 (C-4a), 119,4 (C-9), 118,7 (C-8a), 118,3 (C-5), 117,1 (C-4b), 116,7 (C-1), 112,0 $(\mathrm{C}-2), 108,7(\mathrm{C}-7), 102,8\left(\mathrm{O}-\mathrm{CH}_{2}-\mathrm{O}\right)$ e $56,1\left(\mathrm{OCH}_{3}\right)$; CG/EM t $\mathrm{R}_{\mathrm{R}}=$ 59,980 min, $\mathrm{m} / \mathrm{z}, 294,3[\mathrm{M}]^{+}, 280,8$ (pico base), 252,4, 251,2, 224,3, $195,8,163,3,139,6$ e 137,8 .

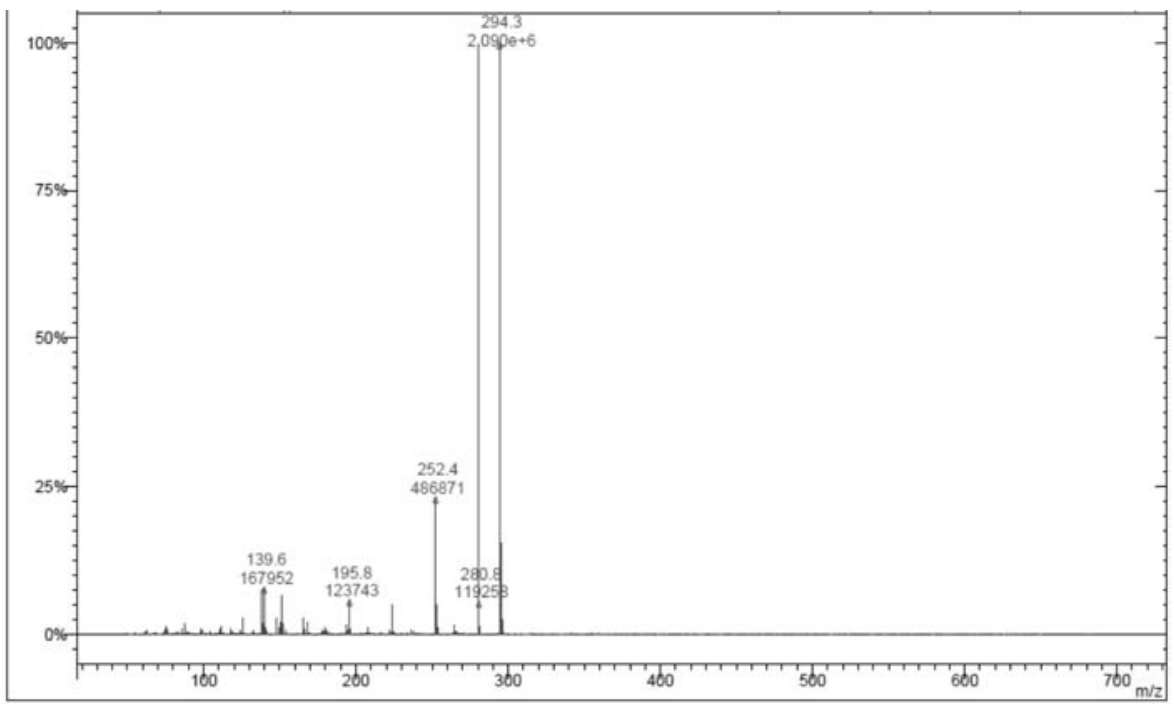

Figura 21S. Espectro de massas de 8 (ácido aristolóquico I)

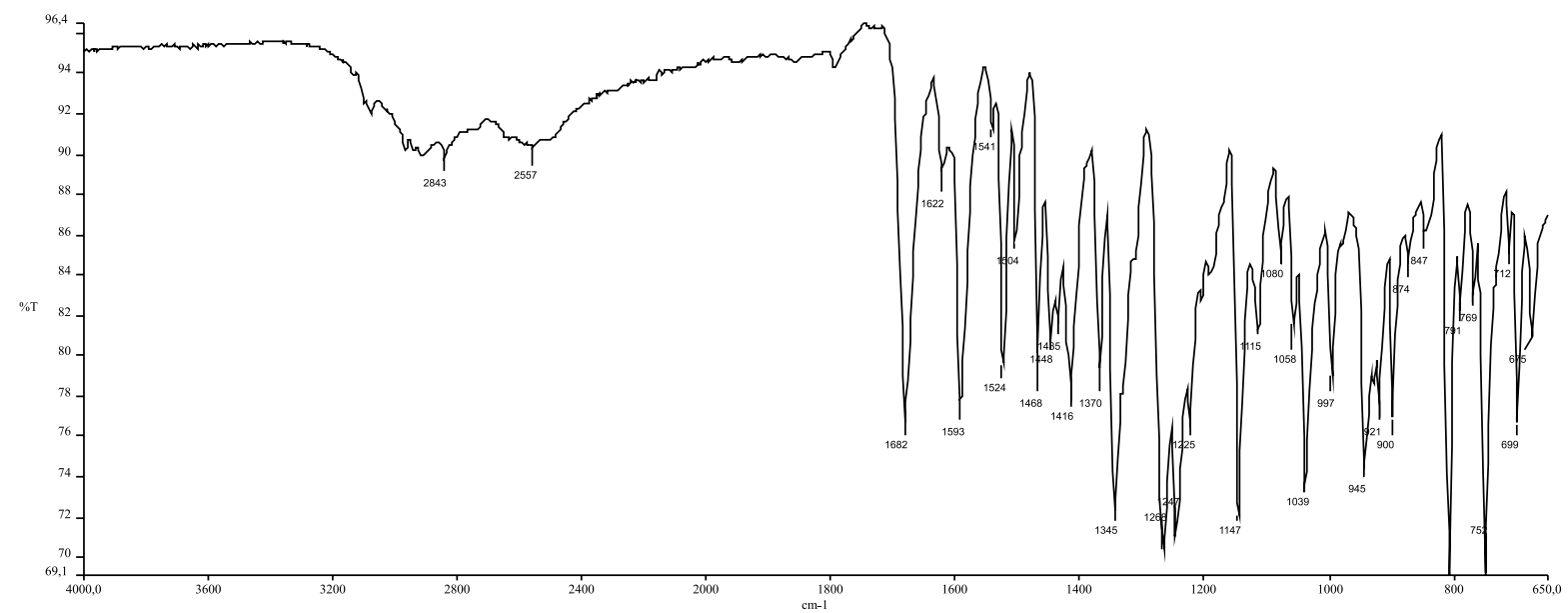

Figura 22S. Espectro de absorção na região do IV de 8 (ácido aristolóquico I; $\mathrm{KBr} ; \mathrm{cm}^{-1}$ ) 
S20

Pacheco et al.

Quim. Nova

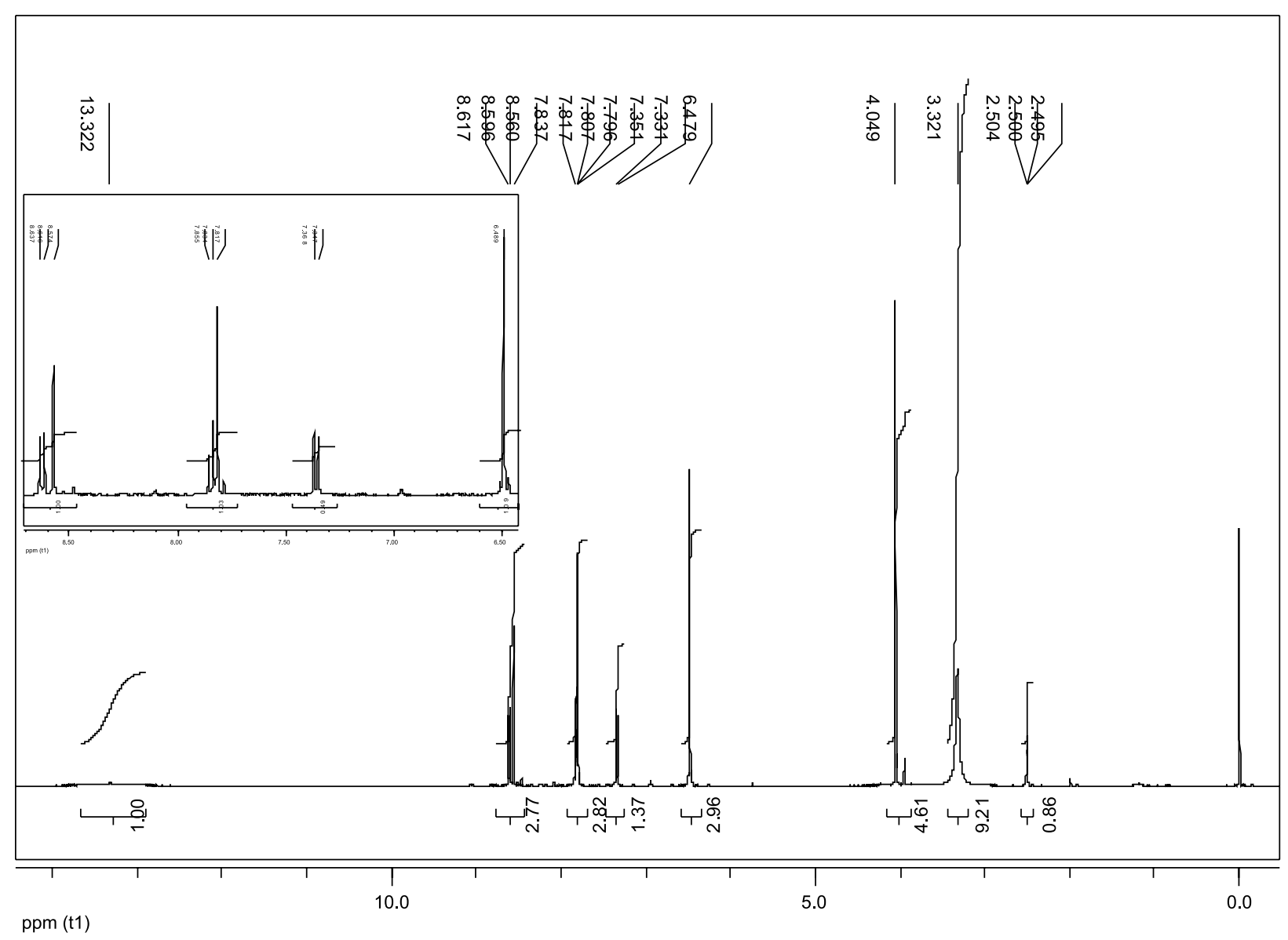

Figura 23S. Espectro de $R M N$ de ${ }^{l} \mathrm{H}$ de 8 (ácido aristolóquico I; $400 \mathrm{MHz}$; DMSO-d ) $^{2}$ 


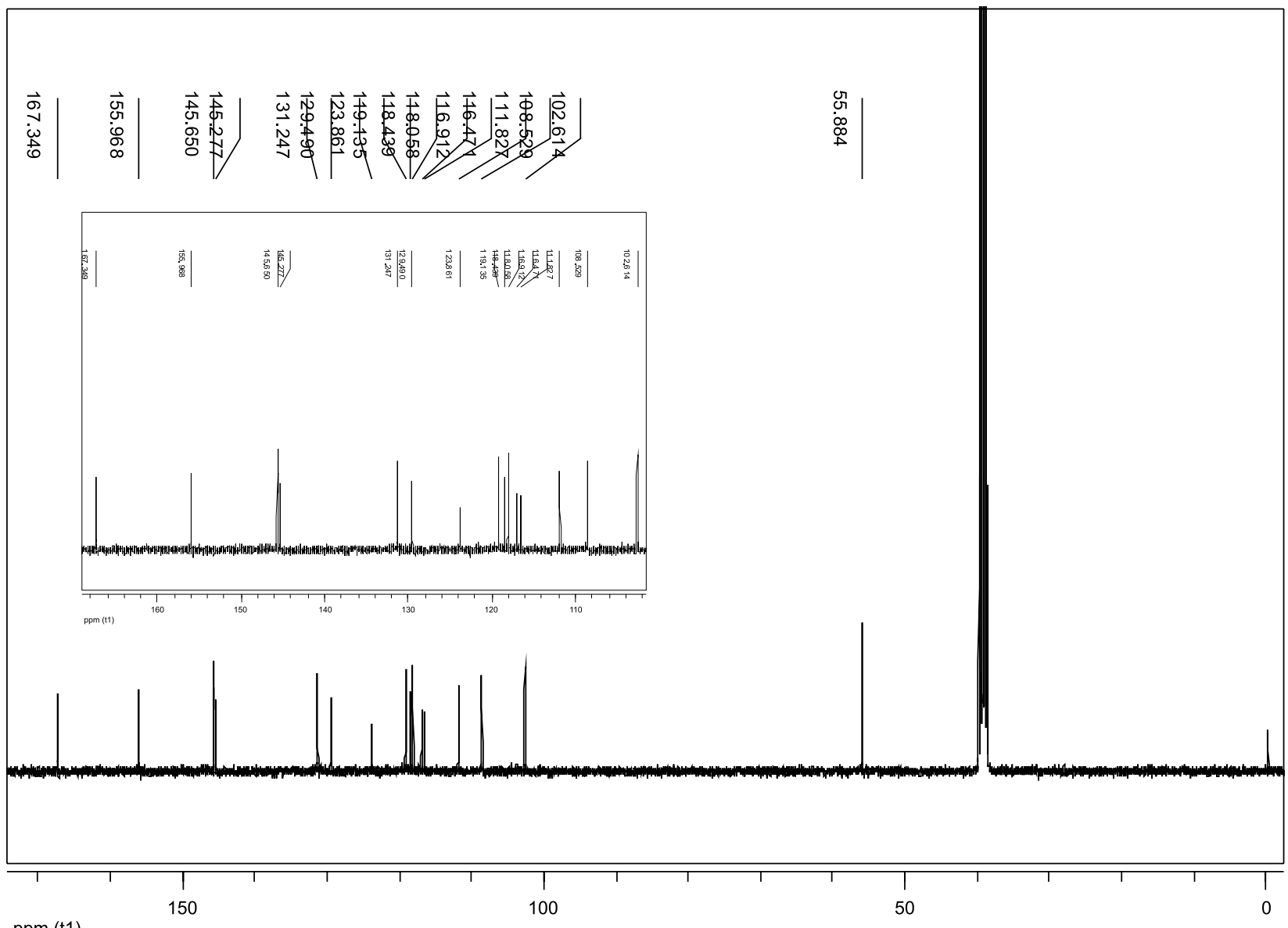

ppm (t1)

Figura 24S. Espectro de $\mathrm{RMN}$ de ${ }^{13} \mathrm{C}$ de 8 (ácido aristolóquico I; $100 \mathrm{MHz}$; DMSO-d ${ }_{6}$ )

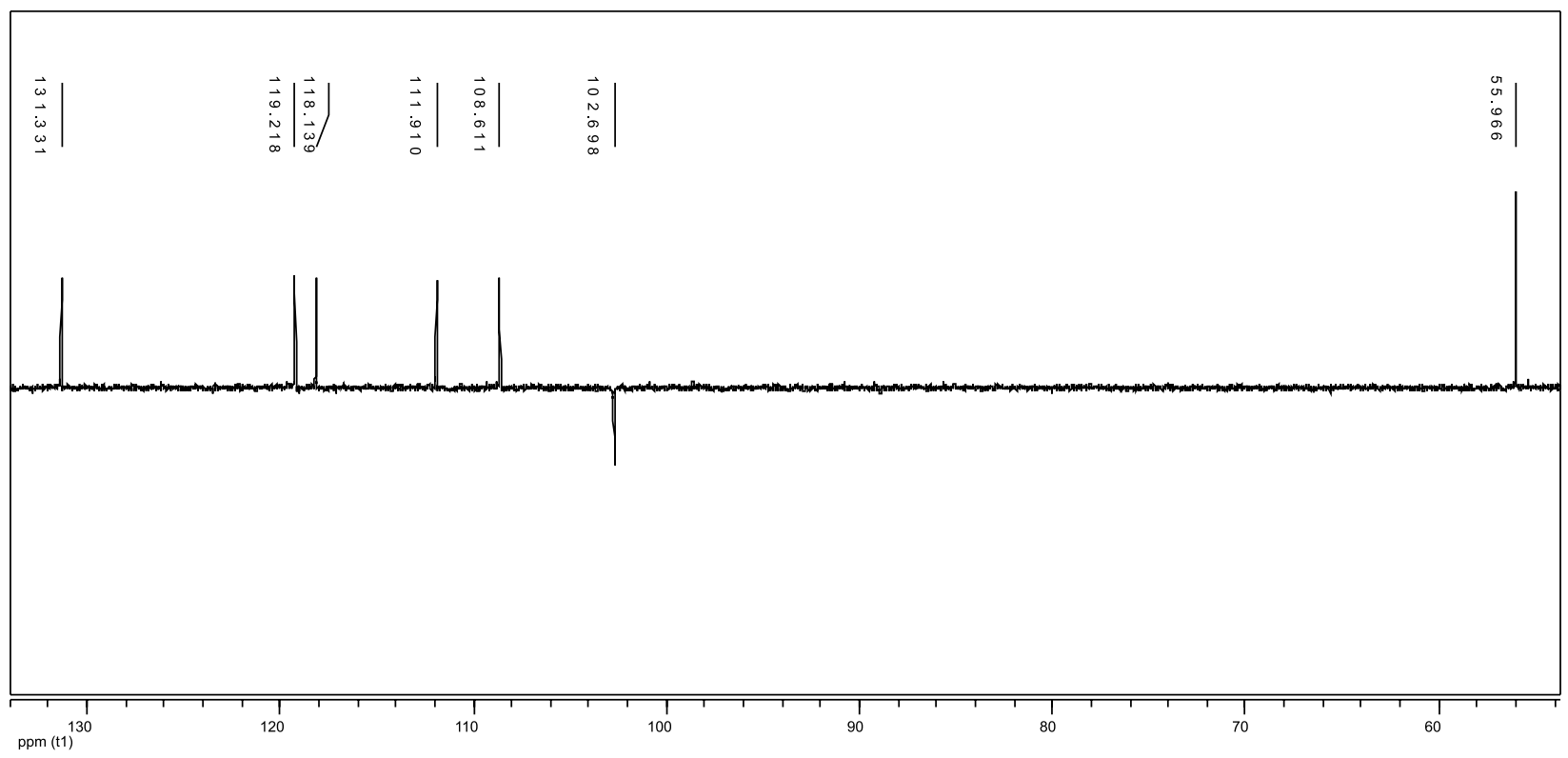

Figura 25S. Subespectro DEPT $135^{\circ}$ de 8 (ácido aristolóquico I; $100 \mathrm{MHz}$; DMSO-d $)$ 


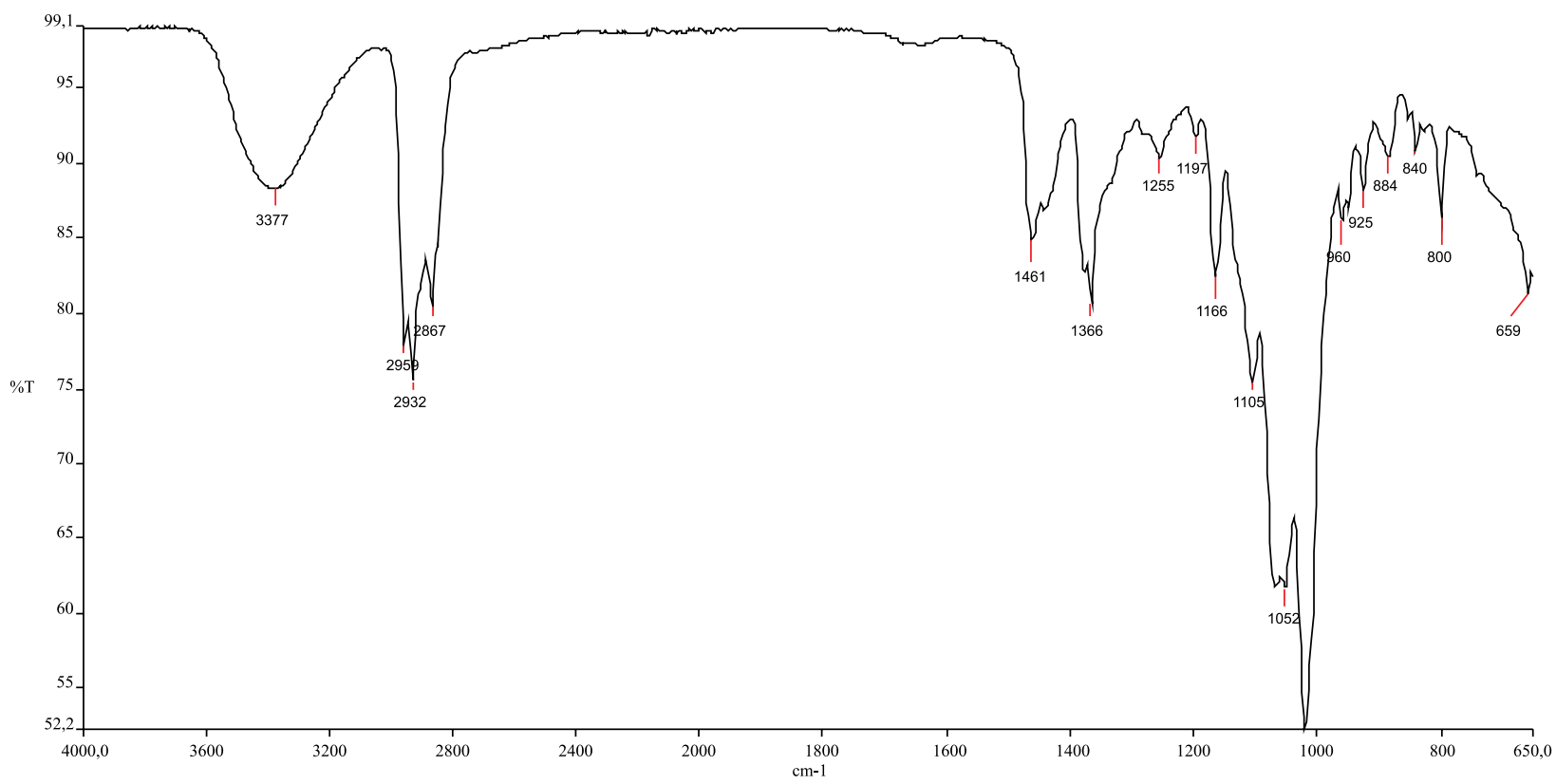

Figura 26S. Espectro de absorção na região do IV de 9 (sitosterol-3-O- $\beta$-D-glicopiranosídeo; $\mathrm{KBr}$; $\mathrm{cm}^{-1}$ )

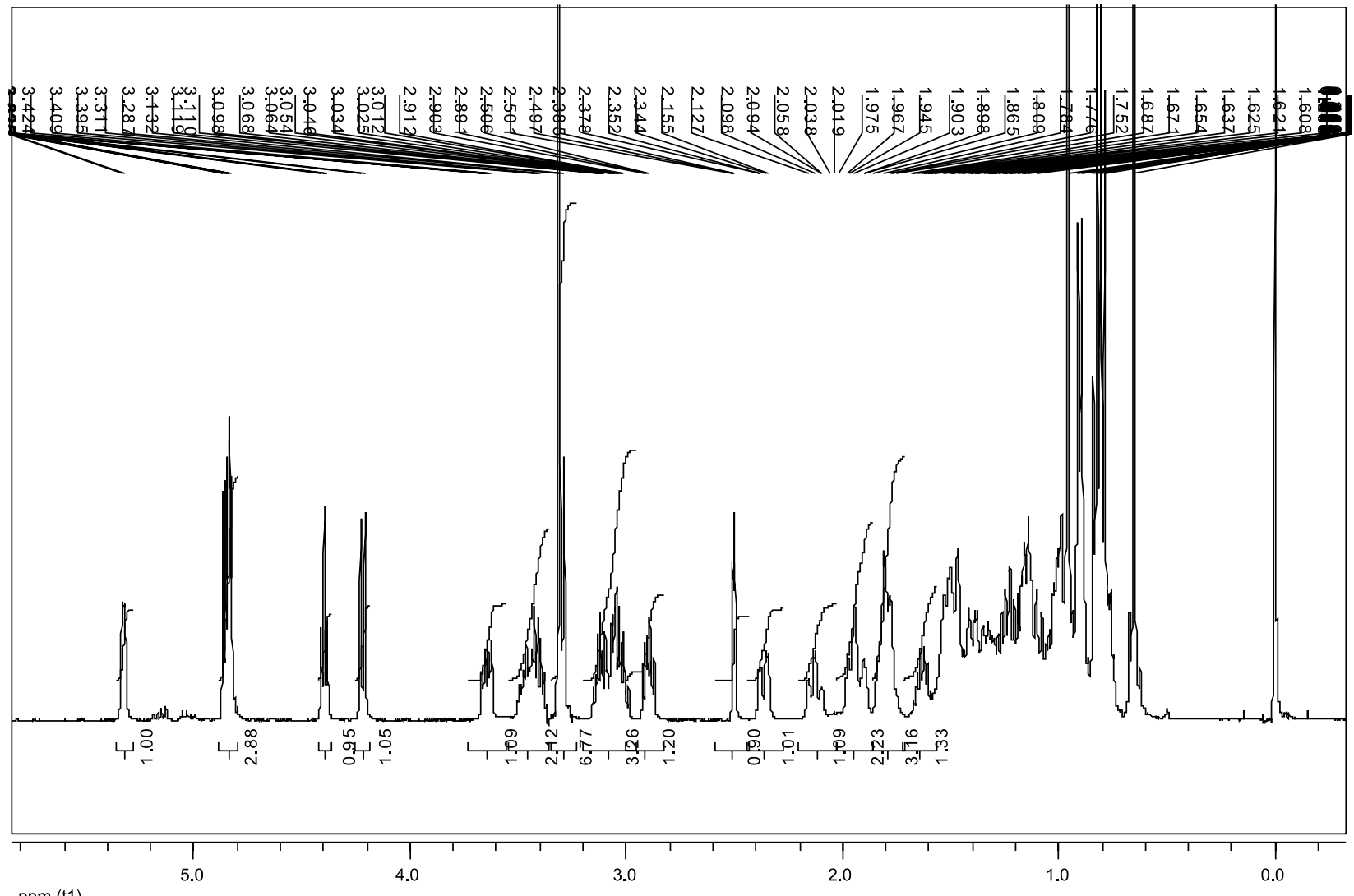

ppm (t1)

Figura 27S. Espectro de RMN de ${ }^{1} \mathrm{H}$ de 9 (sitosterol-3-O- $\beta$-D-glicopiranosídeo; $400 \mathrm{MHz}$; DMSO-d $)$ 

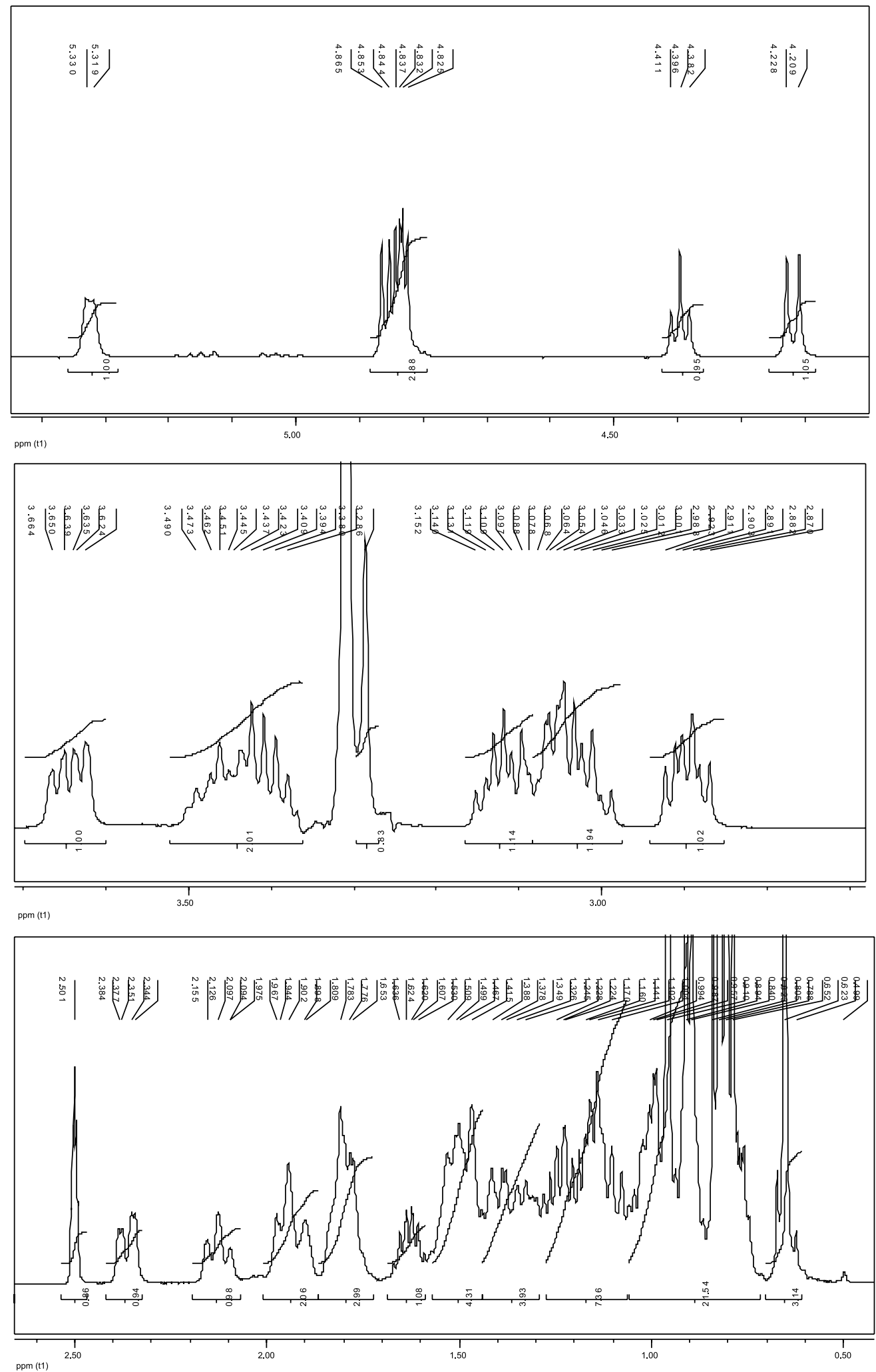

Figura 28S. Expansões do espectro de $R M N$ de ${ }^{l} \mathrm{H}$ de 9 (sitosterol-3-O- $\beta$-D-glicopiranosídeo; $400 \mathrm{MHz}$; DMSO-d ${ }_{6}$ ) 

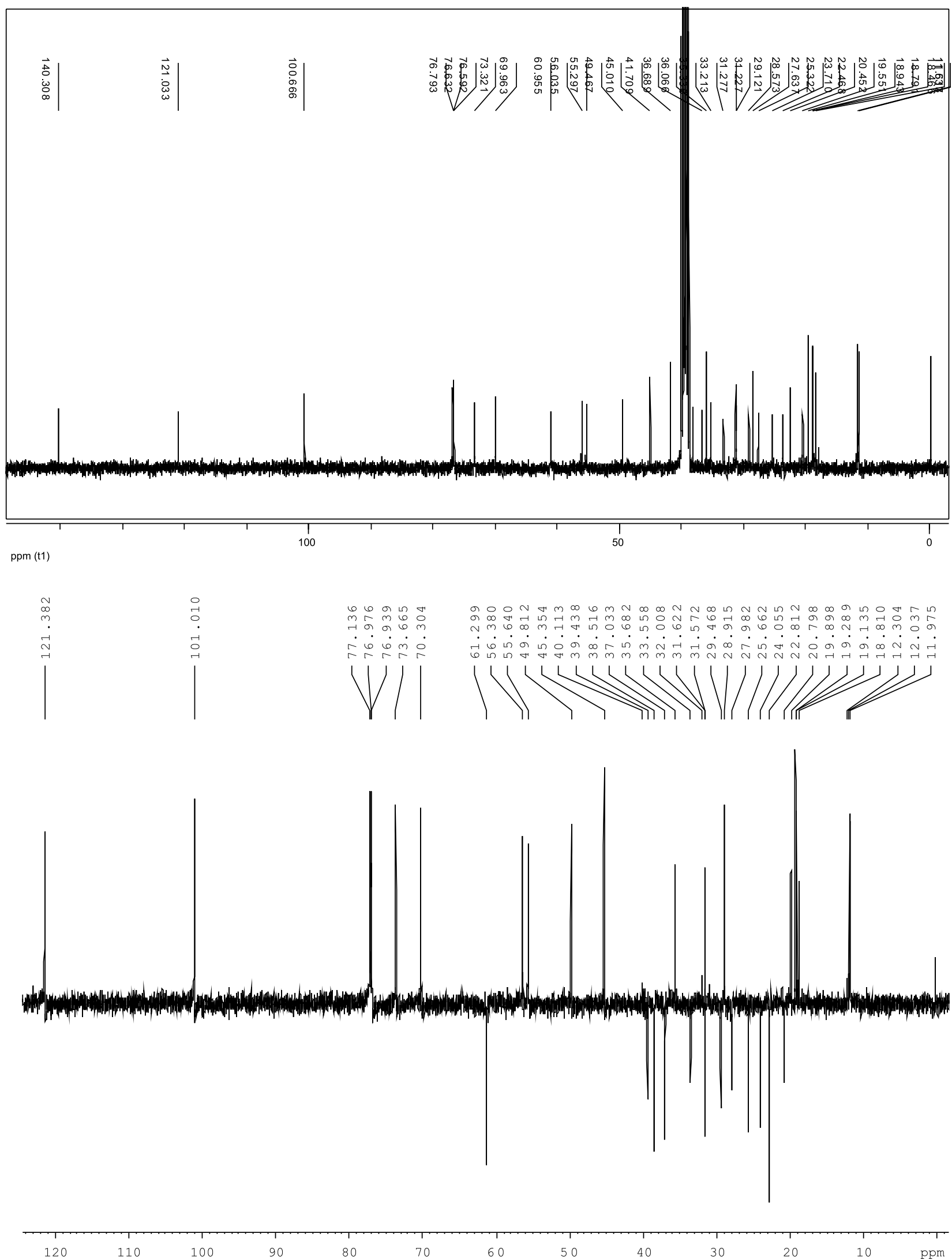

Figura 29S. Espectro de RMN de ${ }^{13} \mathrm{C}$ (superior) e subespectro DEPT $135^{\circ}$ (inferior) de 9 (sitosterol-3-O- $\beta$-D-glicopiranosídeo; 100 MHz; DMSO-d ${ }_{6}$ ) 


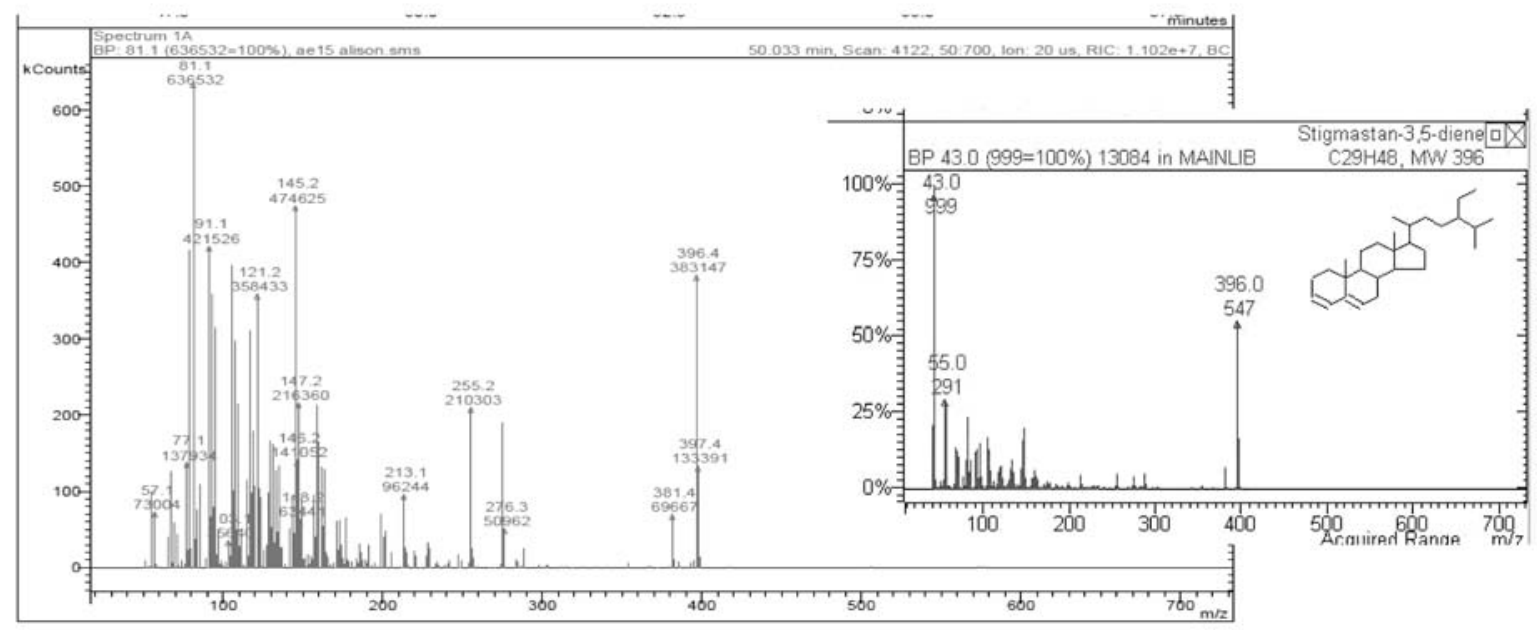

Figura 30S. Espectro de massas de 10 (estigmastan-3,5-dieno) e espectro de massas correspondente do banco de dados NIST (2005). 